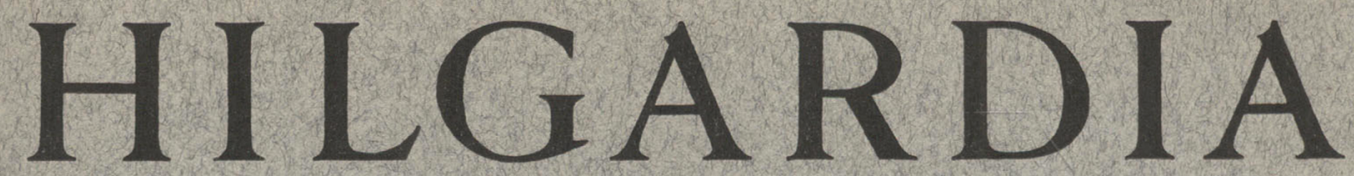

A Journal of Agricultural Science Publisbed by the California Agricultural Experiment Station

CONTENTS

\title{
VASCULAR DIFFERENTIATION IN THE PEAR ROOT
}

\author{
KATHERINE ESAU
}

\section{ONTOGENY OF THE VASCULAR BUNDLE IN ZEA MAYS}

KATHERINE ESAU 


\section{ONTOGENY OF THE VASCULAR BUNDLE}

IN ZEA MAYS

KATHERINE ESAU 



\title{
ONTOGENY OF THE VASCULAR BUNDLE
}

\section{IN ZEA MAYS}

\author{
KATHERINE ESAU ${ }^{2}$
}

ContinUing THE STUDIES on the anatomy of crop plants, with special emphasis on vascular differentiation (Esau, 1936a, 1938, 1940, 1941), ${ }^{3}$ the writer has selected $Z$ ea Mays $\mathrm{L}$. as a representative of the monocotyledons. Though the vascular system of this plant has often been studied (Strasburger, 1891, p. 329-63; Hayward, 1938, chapter 5; Sharman, 1942), the ontogeny of the vascular strand merits further detailed investigation in view of the many unsolved problems of vascular differentiation in the monocotyledons. (See review by Esau, 1943.) The present paper concerns, first, the developmental relation between the vascular tissues and the bundle sheath-a structure characteristic of the vascular bundles in the Gramineae. Second, it attempts to elucidate the nature of the meristem producing the vascular bundles. Literature gives conflicting answers to the question whether this meristemsome or all of it-should be interpreted as procambium or cambium. (See review by Esau, 1943.)

The vigorous vegetative side shoots used as material for slides were obtained from the plants of the Golden Cross Bantam variety, growing in an open field. In preparing the permanent slides a common paraffin method (Esau, 1941) was followed. Free-hand sections were employed for examining the gross structural features.

\section{THE MORPHOLOGY OF THE VASCULAR BUNDLE}

For clarity the structure of the vascular system and of the mature vascular bundle will be considered before the ontogenetic details. Since the recent works on this subject (Hayward, 1938; Sharman, 1942) have not cited Strasburger's (1891, p. 329-63) thorough treatment of the morphology of the vascular tissues in Zea Mays, his description is here reviewed in the light of the present observations and the findings of other investigators.

The Vascular System.-In common with the other monocotyledons, $Z e a$ has numerous "parallel" vascular bundles in the leaf blade and the leaf sheath. (Since the bundles converge and fuse at the tip of the leaf, they are not truly parallel.) Large bundles alternate with small. Within the stem the prolongations of the leaf strands, the leaf traces, appear as

\footnotetext{
${ }^{1}$ Received for publication October 20, 1942.

${ }^{2}$ Assistant Professor of Botany and Assistant Botanist in the Experiment Station.

${ }^{3}$ See "Literature Cited" for complete data on citations, mentioned in the text by author and date of publication.
} 

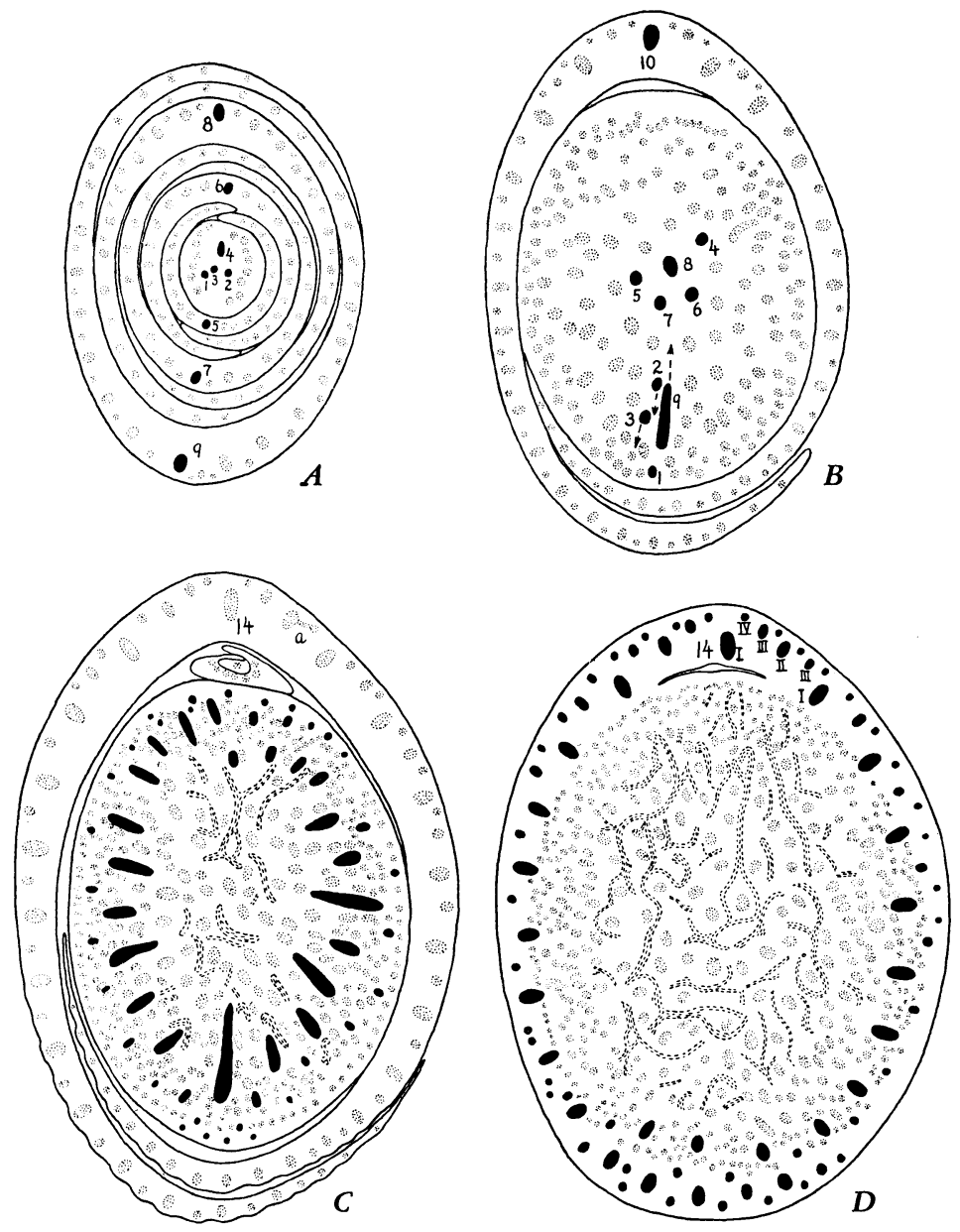

Figure 1.-Diagrams of transverse sections through a shoot taken the following number of microns below the apex: $A, 450 ; B, 1,030 ; C, 2,690 ; D, 3,320$. One or more leaves ensheathe the stem in $A$ to $C$. In $A$ and $B$ the median leaf bundles or traces are shown in black. Traces 1 to 3 appear in their median positions within the stem in $A$, but are near the periphery in $B$. The arrows in connection with the traces 2 and 3 in $B$ indicate that these two traces occurred still nearer the periphery at lower levels of the stem. In $C$ the traces of leaf 13 are shown in black. The large traces, which at lower levels occur near the center of the stem, have at level $C$ a somewhat oblique transverse course. In $D$ the traces of leaf 14 are shown in black. The traces of leaf 13 in $C$ were cut below the insertion of leaf 13 , whereas the traces of leaf 14 in $D$ appear at the level where leaf 14 is united with the stem. The small curved bundles indicated by broken lines in $C$ and $D$ are the horizontal traces leading to the axillary buds and adventitious roots. At $a$ in $C$ appears a transverse connection between two longitudinal strands in leaf 14. The Roman numerals in $D$ indicate the order of appearance of the bundles accompanied by these numbers. ( $A$ and $B, \times 20$; $C$ and $D, \times 10$.) 
scattered vascular bundles (fig. 1, B). The different traces of one leaf occur at different depths within the stem. If the traces of a given leaf are studied in successive sections, downward from the node at which this leaf is attached to the stem, their course is as follows: Within the node the large bundles bend inward, whereas the small ones remain near the periphery of the stem (fig. 1, $C$ ). The median bundle bends so strongly that it approaches the center of the stem. In figure $1, A$, the median traces 1, 2, and 3 appear in their innermost positions; trace 4 is approaching such a position. In figure $1, B$, the median traces 4 to 8 occur around the center of the axis. The other large bundles come to occupy intermediate positions between the peripheral and the central. With slight alterations in their positions the traces extend downward within the stem through several internodes; then the larger traces become clearly reoriented to a peripheral position. Figure $1, B$, shows the median trace of leaf 1 in a peripheral position, whereas traces 2 and 3 are approaching this position. Usually the median trace appears in its peripheral position on the side of the stem opposite the median part of the leaf to which this trace belongs. In this respect traces 1 and 3 in figure $1, B$, deviate from the ordinary condition. The reorientation of the large traces is accompanied by a basipetal diminution in size, so that in their peripheral prolongations these traces are as small as the leaf traces whose longitudinal course is entirely peripheral.

The vascular system of $Z e a$ closely corresponds with that of the socalled "palm-type," whose features Haberlandt (1914, p. 383) sums up. Sharman (1942, p. 259) opposes this comparison because the large bundles lateral to the median "do not approach the center of the stem, but maintain a vertical course." Figure 1, $C$, shows that the large lateral traces, as well as the median, have a horizontal course at the node and approach the center of the axis, though finally the laterals occupy a less central position than the median strand.

The traces of a given leaf remain discrete through variable lengths of the stem. Strasburger (1891, p. 351-52) found the larger traces to be free of connections through longer distances than the smaller bundles. He followed the median traces through about six internodes. Sharman (1942) and the present writer distinguished median strands within eight or more internodes in the youngest shoot parts. Traces 1 and 2, for example, are still discrete in the ninth internode in figure 1, $B$. The smallest peripheral bundles may fuse with others at the first node or may continue free to the next lower node (Strasburger, 1891).

Certain horizontal bundles occur in the nodal plates and in the peripheral portion of the internodal base (fig. 1, D). In plate 10 these bundles are cut mostly transversely and appear as small groups of 
dense cells among the large longitudinal traces. According to Strasburger (1891, p. 346-47), the horizontal bundles of the internode rise from the node below and connect with the axillary buds and the adventitious roots. Sharman (1942) places all the horizontal bundles in the base of the internode, interpreting them as prolongations of the youngest peripheral traces formed after these traces reach the base of the internode in their basipetal course of development. Judging by the position of the leaf bases and the horizontal bundles, the section in plate 10 does not substantiate Sharman's statement that horizontal bundles are not formed within the node. In addition, figure $1, C$, shows some transverse bundles at the same level where the traces of leaf 13 have a horizontal course within the node of this leaf.

The Vascular Bundles of the Leaf Sheath, the Internode, and the Node.-The vascular strands vary in structure in the different parts of their course. There are also differences between bundles of different size. Plate $9, B$, depicts a large bundle from a leaf sheath. In structure it resembles the central bundles of the internode. (Compare with plate 25 in Artschwager, 1925:) It is the best-known type of $Z e a$ bundle. The xylem and the phloem are arranged collaterally and, when mature, enclose no meristem between them. The tracheary elements of the protoxylem (annular and spiral vessels), which mature before the stem or the leaf elongates, are disintegrated in the mature bundles; in their place appears a large intercellular space, the protoxylem lacuna (plate $9, B, l)$. The lacuna is surrounded by xylem parenchyma. Frequently an annular or spiral vessel appears in the median position of the bundle next to the lacuna (plate $9, B$ ). Since this vessel matures after the elongation of the stem or sheath and is not destroyed by this growth, it may be regarded as the first metaxylem element. On both sides of the bundle (plate $9, B$ ) occur two other large metaxylem vessels, usually with pitted or reticulate-pitted secondary walls. The small-celled tissue between the two lateral metaxylem vessels (in contact with them) is a mixture of xylem parenchyma and narrow tracheary elements. The latter are small vessels (Strasburger, 1891, p. 330; Cheadle, 1942), varying in number; some of them usually touch the large vessels (plate $9, B)$. Like the conducting elements, the parenchyma of the metaxylem has lignified walls and prominent elongated pits.

The phloem is composed of rather large sieve tubes and small companion cells in a more or less orderly pattern. The phloem shown in plate $9, A$ and $B$, is metaphloem. The protophloem is crushed in mature bundles (obl in plate 9 ). The last procambial cells between the xylem and the phloem differentiate as parenchyma, which separates the two conducting tissues from each other. This separation is not necessarily 
complete. Phloem cells (companion cells and sieve tubes) frequently are in contact with the lignified xylem parenchyma. (In plate $9, B$, the sieve tube at $s t$ and its companion cell lie next to a xylem-parenchyma cell.)

The large bundles are enclosed in a bundle sheath having lignified walls. The sheath cells are compactly arranged, with no intercellular spaces among them or between them and the vascular cells. At the xylem and the phloem poles of the bundle the sheath is two to several layers thick, the cells being sclerenchymatous, long, and tapering. On the flanks of the bundles the sheath cells are shaped like parenchyma cells; they have rounded pits, in contrast to the slitlike pits of the prosenchymatous sheath cells. Often the sheath is uniseriate on the flanks of the bundle (plate 9, $B$ ); but it may be thicker. As far as could be ascertained, the sheath cells have protoplasts in mature state, in agreement with Strasburger's (1891) description.

The sheath cells are in contact with the xylem parenchyma and frequently also with the two lateral metaxylem vessels (plate 9, $B$ ). According to Strasburger (1891), no pits occur between the vessels and the sheath cells, although these structures are very prominent between the vessels and the xylem parenchyma cells. The sheath cells touch the crushed protophloem, but are separated from the metaphloem by a layer of parenchyma (plate $9, B$ ). According to Strasburger (1891), these parenchyma cells may show lignification in the walls adjacent to the sheath.

The small peripheral bundles of the stem and the small strands of the leaf sheath have less vascular tissues and smaller bundle sheaths than the large bundles. Since the smallest bundles mature after the organs containing them have ceased to elongate, they show little effect of stretching. No protoxylem lacuna is present, or the protoxylem and the protophloem are entirely lacking.

The central or near-central bundles that traverse the nodes vertically also show little effect of elongation in the nodal region, in that their protoxylem is not converted into a lacuna. Fusions of bundles are common in this region. Traces having a horizontal course in the node (fig. 1, $C$, the large traces of leaf 13) show an arrangement of tissues different from that in the longitudinal bundles: the xylem tends to surround the phloem (amphivasal bundles). The nodal anatomy is further complicated by anastomoses, fusions, and the connections with the horizontal system already mentioned (fig. $1, D$ ).

The Bundles of the Intercalary-Meristem Zone.-Zea, in common with the other Gramineae, has the so-called "intercalary-meristem" regions at the base of each leaf sheath and each internode of the stem. 
It is commonly stated in the literature that these meristems cause the internodes and the leaf sheaths to elongate for some time after being laid down by the apical meristem (Troll, 1935, p. 109). As Haberlandt (1914, p. 182) implies, fundamentally the intercalary elongation of the shoots in the Gramineae is comparable with that of the dicotyledonous stems. Haberlandt also points out that "there are comparatively few Phanerogams in which cell-formation and -extension are strictly confined to the apical region of the axis and the youngest internodes." In the Gramineae and the Cyperaceae, however, the intercalary growth is very striking, since it appears to be rather clearly separated from the apical growth and occurs within a comparatively short period of vegetative growth. According to Haberlandt (1914, p. 183) and others, the intercalary regions remain "permanently meristematic"; that is, after the shoot has reached its mature length through the activity of the apical and intercalary meristems, the bases of the leaves and of the internodes can elongate further because of the special characteristics of the intercalary zones.

The present observations on the manner of growth of the shoot apex in Zea agree essentially with Sharman's (1942). In the youngest portion of the shoot the internodes as such do not exist; they develop through cell division at the base of the leaf-insertion disks. The insertions of the two superposed leaves are thereby separated from each other. In other words, the nodes are removed from each other by intercalary growth. The closeness of origin of two superposed nodes is emphasized by the common origin of the axillary bud of the lower leaf with the base of the next higher leaf. The axillary bud becomes separated from the upper leaf by the interpolation of the internode. The bud, then, according to Sharman, is associated with the internode of the leaf above and not with the leaf in whose axil it appears. Rösler (1928) has previously given the same interpretation of the origin of internodes and axillary buds in wheat. Similarly Evans and Grover (1940) concluded that the bud of a grass develops at the base of a "phytomer" (the unit of structure of the shoot composed of an internode, the leaf at its upper end, and the bud at its lower end) in the axil of the leaf that crowns the "phytomer" next below.

As Sharman has shown, the internode grows by orderly transverse divisions giving rise to longitudinal files of cells. Plate 10 illustrates this phenomenon. The longitudinal section depicted in this plate passed through two nodes $(n)$ and one internode $(i n)$ between the bases of two leaves $(l b)$, which were approximately the sixteenth and seventeenth from the apex. The nodes are characterized by the complexity of their vascular systems, but the young internode is composed of longitudinal 
files of parenchyma (rib meristem) and of vertical strands of vascular tissue. This internode is in a state of division throughout its length. Later, the meristematic activity becomes confined to the base of the internode (Sharman, 1942). The leaf elongates similarly by intercalary growth, during which the cell divisions are gradually localized in the intercalary-meristem zone of the leaf sheath.

Whether represented by the young internode (or leaf sheath) or by a restricted region in the elongated internode (or leaf sheath), the intercalary "meristem" is a partly differentiated tissue region. Its degree of differentiation varies during the different stages of development of the organ containing it. As the internodes elongate, the dividing parenchyma cells of these regions show increasing vacuolation, and the vascular bundles differentiate through them. The vascular strands passing through the growing internode in plate 10 had mature protoxylem and protophloem. After the shoot parts have elongated, the metaphloem and metaxylem mature. Most parts of the plant become structurally rigid : the last vessels develop pitted walls, the bundle sheath is sclerified, and the hypodermal sclerenchyma forms its thick lignified walls. The final elaboration of the intercalary zones occurs, however, in relation to the retention of meristematic potentialities in these zones. The vascular bundles show a small amount of lignified tissue; and the vessels are of the annular and spiral types, these vessel types being directly continuous with pitted elements above and below. (This observation was reported by Strasburger, 1891, and is confirmed in the present study.) The bundles are not encased in a sheath of lignified cells, but are accompanied by a collenchymatous tissue in the form of massive sheaths or bundle caps. No lignified hypodermal sclerenchyma is formed.

Artschwager (1925) describes similar modifications of bundles in the intercalary-meristem regions in the sugar cane and gives further details on the variations in the structure of a grass bundle in the different parts of the shoot.

The Leaf-Blade Bundles.-The vascular bundles in the flat part of the leaf blade can be divided roughly into three groups according to size and structure. The largest (fig. 2, $E$ ) have a lignified sheath confluent with the hypodermal sclerenchyma. The sheath cells on the flanks of the bundle are shaped like elongated parenchyma cells and contain abundant large chloroplasts. In figure 2, $E$, the plastids are indicated by stippled circles. The uniseriate sclerenchymatous sheath layers on the xylem and phloem ends of the bundle (confluent with the hypodermal sclerenchyma) are free of chloroplasts. The bundle in figure $2, E$, has two large lateral metaxylem vessels. Below these is an annular protoxylem vessel, which appears like a space because it is much extended 

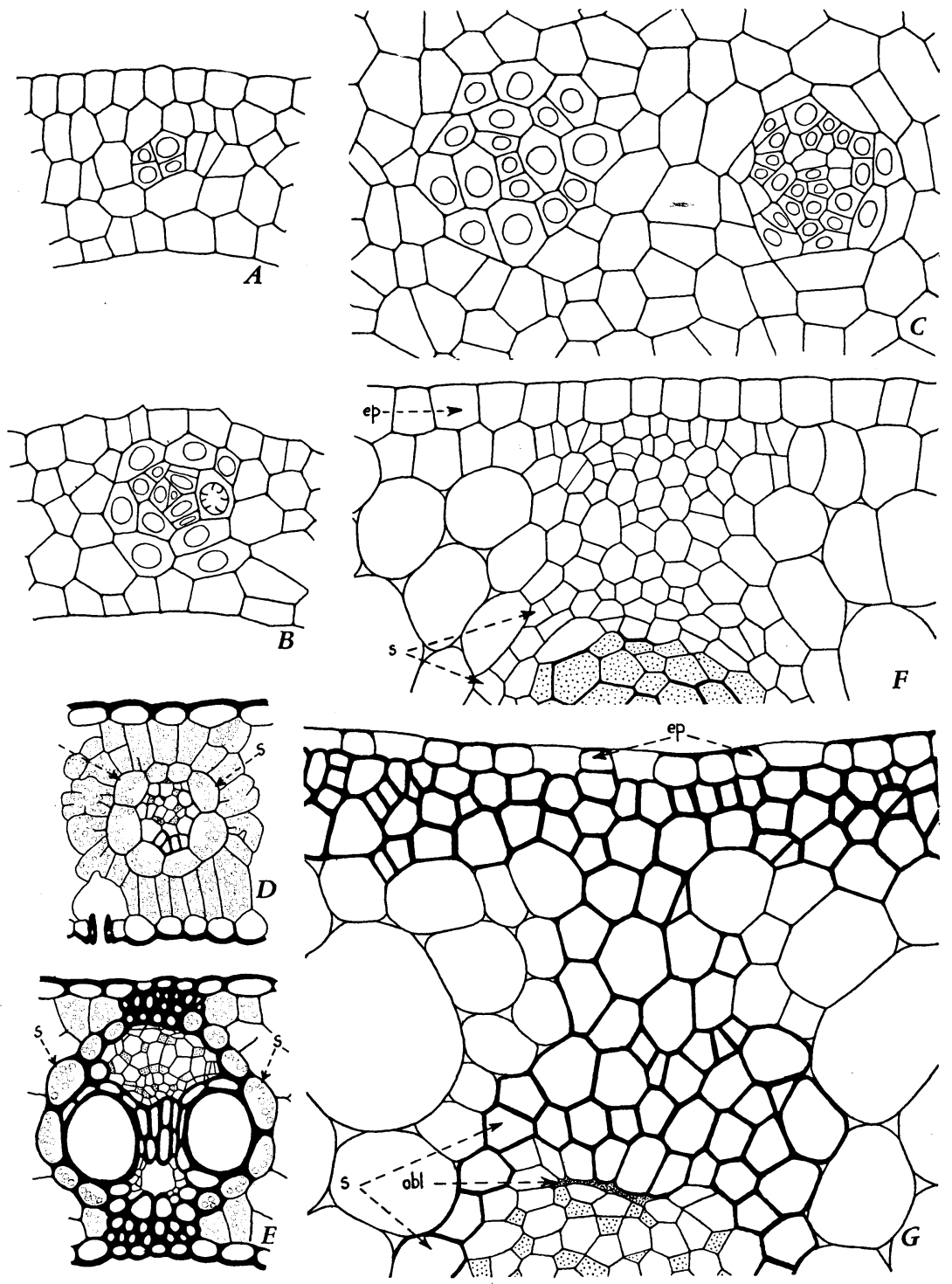

Figure 2.- $A$ to $C$, Transverse sections from leaf $(A, B)$ and stem $(C)$ depicting early stages in procambial differentiation. The nuclei visible in these sections are indicated only in the cells that were concerned with the formation of the procambium. $D$ and $E$, Transverse sections of mature vascular bundles from a leaf blade. The small cells indicated by stippling are companion cells; the stippled circles represent the chloroplasts. $F$ and $G$, Transverse sections of portions of leaves illustrating two stages in the differentiation of the adaxial part of the bundle sheath and of the hypodermal sclerenchyma. $F$ was taken from the same section as plate $5, B ; G$ from the section as in plate $9, B$. In $F$ the entire visible part of the phloem is stippled; in $G$ only the companion cells. Details are: $e p$, epidermis; obl, obliterated protophloem; $s$, sheath. ( $A$ to $C, F$ and $G, \times 467 ; D$ and $E, \times 160$.) 
longitudinally and because the ringlike thickening does not occur in this section. The metaphloem shows the usual composition (sieve tubes and companion cells), and the few protophloem elements appear as flattened cells between the metaphloem and the sheath. According to Cheadle (1942), the presence of vessels in leaf bundles is characteristic of the Gramineae.

The smallest bundles have entirely parenchymatous sheaths rich in chloroplasts (fig. 2, D). The walls of the sheath cells are somewhat thicker than those of the mesophyll, but are not lignified. According to Strasburger $(1891$, p. 336), the sheath cells of the small leaf bundles have cutinized radial walls. The xylem and phloem are much reduced in amount as compared with the large leaf bundles. Strasburger describes the tracheary elements as reticulate-pitted vessels (1891, p. 337, "vessel-like tracheids"). The vascular tissues of these bundles mature after the elongation of the leaf and are here interpreted as metaphloem and metaxylem.

The bundles intermediate in size between the largest and the smallest have parenchymatous sheaths. A hypodermal sclerenchyma strand occurs between the epidermis and the sheath-usually on both sides of the bundle, but sometimes on only one side.

The longitudinal strands of the leaf blade are interconnected by transverse anastomoses. In structure these resemble the smallest longitudinal strands. They contain tracheids (Strasburger, 1891, p. 338) and sieve tubes, and are enclosed in a chloroplast-containing parenchyma sheath. According to Strasburger, sieve tubes are absent in the smallest strands. Similar transverse bundles occur in the sheath (fig. 1, $C$, at $a$ ).

The midvein contains many bundles, the largest resembling the leafsheath bundles in size and structure.

\section{ONTOGENY OF THE VASCULAR BUNDLE}

Initiation of the Procambium.-The ontogenetic details are discussed with reference to the largest leaf-sheath and stem bundles that appear in mature state, such as the bundle in plate $9, B$. One may follow conveniently the different stages in the development of the vascular strands by comparing the bundles in leaves of different ages as seen in transverse sections through a shoot apex (fig. $1, A$, and plate 1 ).

Sharman (1942) has recently described the origin of leaves and the order of appearance of the procambial strands in $Z e a$. Briefly, the leaf formation passes through the following stages: Periclinal divisions in the surface and subsurface cells at the base of the apical cone initiate the leaf buttress. Because of the two-ranked leaf arrangement these 
divisions first occur above and opposite the median part of the next lower leaf. From here the divisions spread laterally around the base of the apical cone to form the encircling leaf base. Before completion of this lateral growth, the small protrusion below the apical cone formed by the first divisions begins to grow upward. Thus apical growth and lateral expansion combine to produce a structure that is highest at the point of its origin and that slopes down along the margins, which are in process of encircling the axis. The two margins advancing toward each other first meet (leaf 4 in plate 1), then overlap (leaves 5 to 9 in fig. 1, $A$, and plate 1). In the early stages of leaf development no boundary is evident between the leaf sheath and the lamina (Sharman, 1942). The following discussion of the procambial initiation will simply use, therefore, the word leaf. Plate 1 illustrates the nature of these leaves as seen in transverse sections.

Before the primordium completes the encircling of the apical cone and when its median part is about 30 to 40 microns high (this was leaf 1 in the shoot used in plate 1), a central procambial strand appears within the primordium. As the young leaf expands laterally, successive procambial bundles differentiate to the right and left of the median. (Compare the leaves of different age in figure 1 and plate 1.) The median and the first series of laterals are, for convenience, classified here as bundles of the first rank or first order (fig. 1, D), since, as a group, they arise first and become the largest in the leaf. Eventually bundles of the second rank are interpolated between those of the first (leaves 7 and 8 in fig. $1, A$ ). Then appear bundles of the third rank (leaves 9 to 14 in fig. 1) and those of the fourth (leaf 14 in fig. 1). Still smaller bundles may be formed (Strasburger, 1891). During the formation of the smallest longitudinal strands, transverse anastomoses arise in the leaf (leaf 14 at $a$ in fig. 1, C). According to Sharman (1942), the median and the large lateral bundles differentiate acropetally within the leaf, whereas the bundles of higher ranks differentiate basipetally and appear at the apex after the laterals reach their highest position. The transverse anastomoses arise after the small longitudinal bundles. These also are formed in basipetal succession (Sharman, 1942). The order of appearance of the smallest bundles is related to the basipetal maturation of the leaves-a characteristic very common among angiosperms.

As shown by transverse and longitudinal sections of the developing leaves, the epidermis is continuous over the leaf margin, and marginal initials add new cells to this tissue layer. Submarginal initials give rise to all the other cell layers of the leaf. Sharman (1942, p. 251) suggests that the dermatogen also may add cells to the inner layers. The earliest (that is, the largest) bundles are initiated when the leaf is five layers 
of cells in thickness. The first divisions indicating the beginning of such a bundle occur in the median of the five layers (fig. 2, $A$ ). First one cell divides; then adjacent cells become involved. The first division of the first cell may be anticlinal, followed by periclinal or oblique divisions of the daughter cells (fig. 2, $A$ ); or the opposite sequence may occur. Figure 2, $B$, and plate $2, A$, show the median procambial strand from leaf 2 of the shoot used for plate 1. The two illustrations were taken from two sections 10 microns apart. In the center of the strand is a group of six small cells that resulted from a recent subdivision of three cells. This group could have arisen from one cell. Certain adjacent cells have also divided or were about to divide around the periphery of the group of small cells. Thus the early divisions initiating a procambial strand appear to spread from a center, the latter being formed by the cells that had divided first. The cells around the central group have a tendency to divide and to elongate tangentially with respect to this group (fig. 2, $B$, and plate $2, A$ ). The products of these divisions become further subdivided by walls of different orientation, but mostly anticlinal with respect to the periphery of the bundle (plate $2, B$ ).

Depending on the size of the bundles, the centrifugal growth of the procambial strands through the addition of cells on its periphery may be smaller or greater. According to Potonié (1886) and the present observations, the extremely small bundles forming the cross connections in the leaves arise entirely within a layer one cell deep and one cell wide.

While the addition of cells occurs on the periphery of the bundle, the cells within it also divide. Since these early divisions are followed by little cell enlargement, the resulting procambial cells are smaller than those from which they arose. Figure 2, $C$, shows graphically the difference in the size of cells at the beginning (bundle to the left) and at a later stage (bundle to the right) of procambial differentiation.

In longitudinal views the procambial cells at a given level of a strand tend to be of the same length, with the transverse walls placed at the same levels. This gives the procambium a storied appearance. The youngest procambial cells are as long as the adjacent parenchyma cells, but rapidly become longer.

After the procambium has thus been organized into strands of narrow elongated cells (plate 2, $B$, bundle to the left), further divisions within the strands increase their thickness in the radial and tangential directions. Since now the cells enlarge somewhat after each division, the size of the procambial cells is not further diminished. When first differentiated the procambium is, as usual, more densely cytoplasmic than the adjacent parenchyma because of the delayed vacuolation in the procambial cells (plate $2, B$, bundle to the left). After differentia- 
tion of the first vascular element (a sieve-tube element) begins, the procambial cells progressively vacuolate. (Compare the successively older bundles in plates $2, B ; 3, A$; and $4, A$.)

The divisions preceding the differentiation of the first sieve tube within the procambial strand are concerned mainly with the radial increase of bundle thickness; that it, they are periclinal with respect to the leaf or stem surface. The cells assume, therefore, a somewhat orderly arrangement, tending toward a radial alignment (plate $2, B$, bundle to the right; plate $3, A$ ). Occasional anticlinal divisions cause the bundles to expand laterally. As the procambial strands increase in circumference, the adjacent parenchyma cells respond by increasing their diameters parallel to the surface of the bundles and by dividing anticlinally to this surface. Occasional periclinal divisions also occur (plates $3, B ; 4 ; 5, A$ ). Because of these divisions the parenchyma cells around a young bundle appear transitional in size between the cells of this bundle and the parenchyma farther removed.

Since the bundles of different ranks are initiated at successively later stages of leaf development, the later strands appear in more obviously vacuolated leaf sections than the earlier. The bundles of the first rank are formed within the rather meristematic leaf tissue. Leaf 4 in plate 1 , for example, shows the first three procambial strands within the still densely cytoplasmic median portion of the leaf. The successive bundles of the first order are initiated closely behind the marginal meristem, as one sees on examining the overlapping meristematic margins of leaves 5 to 7 in plate 1 . The smaller strands (bundles of second, third, and fourth orders) are formed by subdivisions of conspicuously vacuolated cells. (Note the high degree of vacuolation of the median portions of leaves 6 and 7, plate 1, in which the bundles of second rank are initiated.) Similarly in the stem, the first and largest traces arise near the apex in a more densely cytoplasmic tissue than the smaller, later bundles. The small horizontal bundles of stem nodes (fig. $1, D$ ) and the transverse connections in the leaves appear among the latest in their respective organs, and the vacuolation of the cells that become subdivided in the process of their formation is most conspicuous.

The bundles of successive ranks, within the midrib and sheath, seem to arise successively closer to the abaxial side of the leaf (plate $3, B$ ). Actually they all are initiated in the second layer of cells from the abaxial epidermis. The apparent extreme peripheral origin results from the increase in thickness of the median leaf portions through adaxial meristematic activity. Eventually, because of the repeated periclinal divisions, the adaxial periphery of the median part of the leaf appears like a cambium in transverse sections (leaves 6 and 7 in plate 1 ). 
Protophloem and Protoxylem.-As already mentioned, the large bundles are initiated before elongation of the organs in which they occur. Certain phloem and xylem elements (the protophloem and the protoxylem) mature during this elongation and, as is commonly known, become destroyed before the leaf or axis attains its mature size. Though in the xylem the longitudinal stretching appears to be the main cause of destruction of the conducting elements, the protophloem is obliterated even if longitudinal growth is little pronounced. Thus, according to Strasburger (1891) and the present observations, in the nodes of $Z e a$ the protoxylem of the large bundle is not converted into a lacuna, but the protophloem is crushed.

The successive stages in protophloem and protoxylem differentiation may be followed in plates $2, B$, and 3 to 5 . Shortly after the procambial strand is delimited, a sieve-tube element is evident near the outer periphery of the strand. In plate $2, B$ (bundle to the right), this sieve-tube element is immature. Though its walls are already somewhat thick and deeply stained, the cytoplasmic contents are still as dense as in the procambial cells. The first sieve tubes in plate $3, A$, are mature. Their thickened walls and the lack of stainable cell contents make them very conspicuous. Additional protophloem sieve tubes differentiate centripetally from the first, eventually forming a compact cluster of "clear" cells near the outer periphery of the bundle (plate 5, $A$ ). They are bordered by the young sheath cells on the outside and by the procambium on the inside.

The protophloem sieve tubes lack companion cells. They are enucleate in the mature state and have well-developed sieve plates. Their nacré walls (Esau, 1939), though only moderately thick in paraffin material, are thicker than the procambial walls (plate $5, A$ ). Plate $6, A$, shows parts of the somewhat stretched protophloem sieve-tube elements in a longitudinal view (the two lower cells marked with $s t$ ). The inclined end wall to the right $(s p)$ bears a sieve plate, discernible as such under an oil-immersion lens. In this figure the thickness of the walls and the thinness of the protoplasts are obvious. As the protophloem ages and is stretched, the walls become noticeably thinner (plate $5, B$ ). Plate 7 , $A$, shows part of an old protophloem sieve tube in longitudinal view (the upper cell marked $s t$ ). Since its elements are very long, the transverse walls do not appear in this section; the longitudinal walls are very thin, in sharp contrast to those of the adjacent differentiating metaphloem sieve-tube elements (the lower cell marked $s t$ ).

The destruction of the protophloem is depicted in plates $7, B$, and 8 . The thin-walled protophloem sieve tubes are still intact in plate $7, B$ (two of the outer layers of cells marked $s t$ ). The sheath cells $(s)$ 
immediately outside the protophloem have divided periclinally. Their subsequent enlargement, combined with the centrifugal growth of the metaphloem, causes a crushing of the protophloem. The first stage in this process is discernible in plate $8, A$; the second in plate $8, B$. The final stage of protophloem obliteration appears in plate 9 (at $o b l$ ). In old stem parts the obliterated protophloem shows a strong lignin reaction with phloroglucinol and hydrochloric acid.

When two to three protophloem sieve tubes are mature, the first protoxylem element differentiates. The nature of this and of the subsequent protoxylem elements was determined on the basis of their appearance during development. When the differentiating tracheary elements show secondary thickenings on the longitudinal walls, the entire or most of the transverse end wall-the part which is removed just before maturation-remains free of secondary thickenings and is deeply stained. Since the transverse wall is thicker in the middle, it appears somewhat lenticular in shape in the narrowest elements. Because these developmental stages resemble those observed in the differentiating vessel elements of other plants (Esau, 1936b; Esau and Hewitt, 1940), the tracheary protoxylem elements in $Z e a$ are here interpreted as vessels.

Cheadle (1942) has pointed out that in the mature state the spiral xylem elements of the Gramineae cannot well be studied in macerations; they are too much stretched and too difficult to separate from other cells. Cheadle, however, identified spiral vessels in at least one plant organ in twenty-two species of grasses. In the metaxylem, vessels were found in all organs of forty-five species of thirty-three genera of Gramineae.

The first protoxylem vessel is usually annular and appears near the inner margin of the bundle (plate 4, $A$ ). Before the first vessel matures, the xylem end of the procambial strand becomes rather more vacuolated than the phloem end (plate $3, A$ ). Later the phloem region also vacuolates conspicuously (plate 4). The first and the subsequent protoxylem vessels appear, one after the other, in the same radial row of cells, each successive element being wider than the preceding. (Compare the bundles in plates 4 and 5.) During differentiation of the protoxylem the storied appearance of the procambium is disturbed. While the mother cells of the earlier vessels are elongating, those of the later vessels are still dividing by transverse walls, so that the end walls of the successive vessel mother-cell series occur mostly in different horizontal planes. Plate $6, A$, shows, above, a portion of a mature annular protoxylem vessel whose segments are longer than the width of the photograph. Then follows a series of vessel mother cells, considerably expanded, but 
rather short. Transverse divisions have been completed in this series. The end walls already show the characteristics of vessel end walls before dissolution (Esau, 1936b; Esau and Hewitt, 1940). The mother cells of the third series are little expanded and are very short. Obviously this series was still dividing by transverse walls when such divisions ceased in the second series.

The radial alignment of cells in the protoxylem end of the bundle (plates $5, B$, and $9, B$ ) is disturbed by the expansion of the protoxylem vessel segments and by the occurrence of anticlinal and oblique divisions in the adjacent cells. The small cells in this part of the bundle remain parenchymatous (the protoxylem parenchyma).

As previously mentioned, the conducting elements of the protoxylem are destroyed during elongation. When the first vessels are stretched they disappear from view completely, except where a ring happens to occur in a section. Seemingly, in the early stages of this process the parenchyma cells crush the xylem elements. In dicotyledons the xylem parenchyma commonly obliterates the stretched protoxylem cells (Esau, 1936a). In $Z e a$ and other grasses, after several vessels are destroyed, a lacuna is formed because the adjacent parenchyma does not fill the space formerly occupied by the vessels.

The protoxylem vessels mature one after the other and are also stretched successively. Plate $4, A$, shows a protoxylem vessel before stretching. Every section of the bundle showed a ringlike secondarywall deposit, because the rings were still close together. In the bundle in plate $4, B$, the ring appears somewhat tilted. When the rings become widely spaced many sections lack rings (plate 5 , earliest xylem elements in both bundles). At this time the younger vessels still have closely arranged rings or spiral coils.

The Metaphloem and Metaxylem.-As shown earlier, the periclinal divisions and the radial seriation of cells resulting from these divisions become evident in the procambial strands before the first conducting elements mature (plate $2, B$, bundle to the right). This method of cell division continues during the following stages of bundle differentiation. As the cells increase in number, the orderly arrangement of the procambial cells becomes more and more conspicuous (plates 4 and 5). The periclinal divisions occur in several cells of one radial row. In other words, there is no single initial layer like the one commonly thought to occur in the cambium. Nevertheless, in the last stages of cell addition the procambium, as seen in transverse sections, markedly resembles the cambium of the dicotyledons. The dividing cells become limited to a narrow region, and the immediate products of division have short radial diameters (plates $5, B ; 7, B$; and 8 ). The radial 
arrangement of cells is later somewhat obscured in metaxylem-as in protoxylem-by enlargement of vessels, though the small-celled part of the metaxylem may remain in orderly arrangement (plate $9, B$ ). The mature metaphloem reveals by its pattern the origin from a radially seriated meristem (plate 9 ).

Plates 7, $B$, and 8 show the differentiation of the metaphloem. The metaphloem sieve tubes have companion cells. As usual, these cells arise from the same phloem mother cells as the sieve-tube elements with which they are associated. A longitudinal division of the phloem mother cell forms a wide and a narrow cell (plate $7, B$, and $8, B$ ). The narrow cell divides again, at right angles to the first plane of division of the phloem mother cell, so that a vertical file of companion cells is formed in connection with each sieve-tube element. The protoplasts of the differentiating companion cells become denser than those of the cells from which they arose (plates $6, B ; 7, B$; and $8, B$ ).

After the division of the phloem mother cell into the companion cells and the sieve-tube element, the walls of the latter become conspicuously thickened except on the side touching the companion cell (plate $7, B$ ). This, the so-called "nacré" wall (Esau, 1939), appears before the nucleus disintegrates (plate $8, B$, sieve tube with a nucleus, $n$, and a thick wall; plates $6, A$, and $7, A$ ) and shows prominent pit areas (plate $7, A$, indentations in the thick wall of the lower cell marked $s t$ ). The pit areas become sieve areas (Cheadle and Whitford, 1941); the transverse or slightly oblique end walls differentiate as sieve plates. Plate $9, A$, shows at the left (above) a mature sieve plate, in which the lighter dots represent the callus cylinders lining the pores. At this magnification the cytoplasmic connecting strands through the callus cylinders are not discernible.

The early metaxylem vessel that occurs to the left of the lacuna in plate $9, B$, usually begins to differentiate while the organ elongates and shows the effect of this growth in the considerable length of its segments. The two lateral metaxylem vessels are initiated later, are little affected by stretching, and have therefore comparatively short segments. According to Frey-Wyssling (1940), the reduction of the segment length of the last metaxylem vessels, as compared with the earlier vessels, distinguishes $Z e a$ and other Gramineae from the dicotyledons with secondary growth, in which the metaxylem elements are progressively longer.

The Bundle Sheath.-The foundation of the bundle sheath is laid during the early stages of procambial differentiation. The outermost layer of cells in the bundles of plates $2, B, 3$, and 4 is a bundle sheath in its earliest stage of development. The young sheath follows the increase 
in circumference of the bundle by anticlinal divisions (anticlinal with respect to the periphery of the bundle). Then on the xylem end of the strand the sheath becomes two- to several-layered by periclinal divisions (plates $5, B$, and $9, B)$. On the flanks also the sheath may be more than one cell thick. In the first stages of bundle development the sheath is uniseriate outside the protophloem (plates $3, B$, and 4 ). Later, divisions occur within, and also outside, the original sheath layer (plate 5). The cells resulting from the divisions outside are also added to the sheath.

The amount of sheath tissue added to the bundle in its somewhat advanced stage of development varies with the size of the bundle and its location in the plant. Most massive sheaths develop in the intercalarymeristem region. These are the collenchymatous sheaths (or bundle caps) discussed previously. The compound bundles in this region strikingly illustrate the close developmental relation between the sheaths and the vascular tissues. They become compound through the development of additional small vascular strands within the sheath surrounding a larger bundle. Figure 3 illustrates this phenomenon. The vascular tissues at $a$ were the first to differentiate. Cell divisions around this bundle produced the massive sheath. In the outer part of the latter, new vascular groups began to differentiate before the sheath matured into collenchyma. The small strand at $b$ had three sieve tubes with companion cells (stippled cells) and a tracheary element, still immature but with secondary walls. In the bundle at $c$ two sieve tubes with companion cells were present, and a tracheary element without secondary thickenings. The bundle at $d$ showed only an incompletely expanded tracheary element. Although certain cell divisions had occurred around it, no phloem elements had yet differentiated.

The lack of developmental distinction between the sheath and the vascular tissues is revealed also by other bundles. Thus the first xylem element may differentiate from a sister cell of a young sheath cell; and in the small transverse anastomoses the vascular elements and the sheath cells arise from the same parenchyma cell. Then, of course, in the earliest stages of procambial initiation the future vascular cells cannot be separated from the future sheath cells (fig. 2, $A$ to $C$; plate 2, $A$ ).

Similarly, there is no clear demarcation between the sheath and the adjacent tissues on a developmental basis. It has been shown that the procambial strand grows first by the addition of cells on the periphery through division of cells adjacent to the bundle. Often, after the last of these divisions, half of a cell is added to the bundle, whereas the other half remains outside. Then, as already mentioned, new sheath cells may be added to the bundle in the later stages of its development.

The lack of demarcation between the bundle sheath and the adjacent 
tissue is most obvious in the bundles that are in contact with the hypodermal sclerenchyma in stem and leaves. This tissue is initiated at the time when the bundle sheath is being thickened by the division of cells located outside the protophloem end of the bundle. The hypodermal sclerenchyma originates by longitudinal divisions of the parenchyma

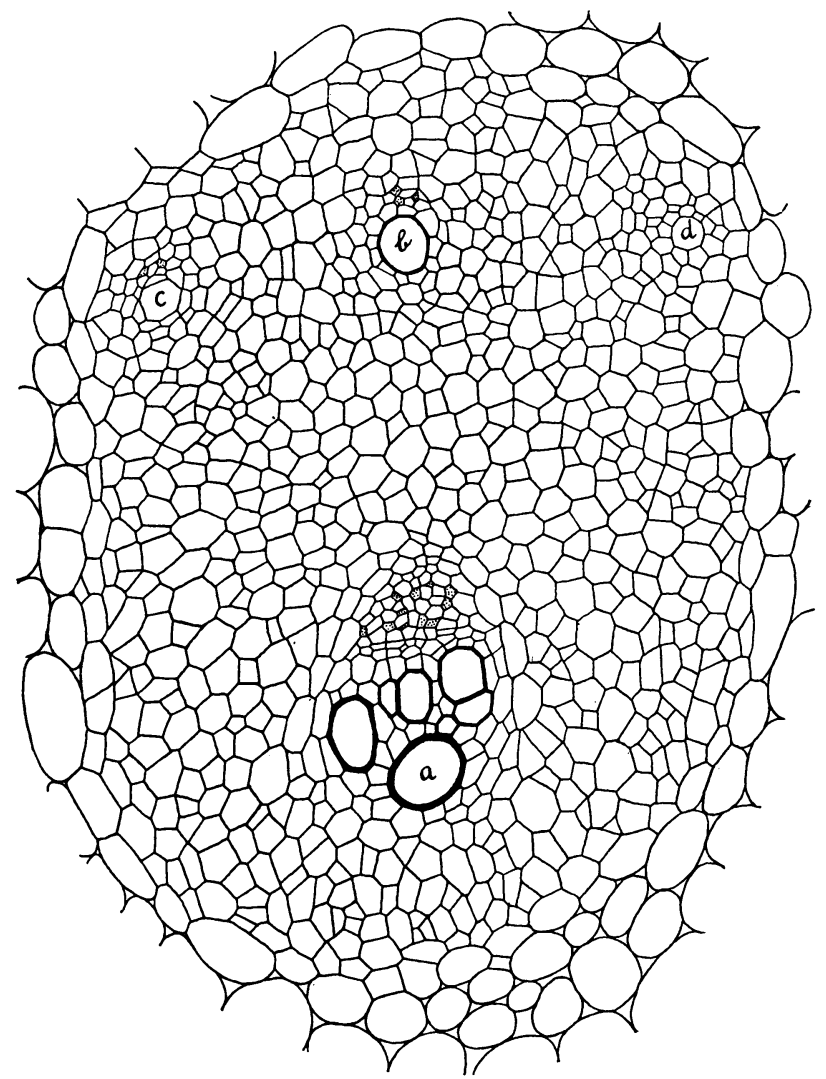

Figure 3.-Transverse section of an immature bundle from the intercalarymeristem region of a leaf sheath. This bundle is a compound structure. Four vascular strands $(a$ to $d)$ are imbedded in a comparatively small-celled tissue, which at maturity becomes collenchymatous. The vascular strands are in different stages of development, that in $a$ being the most advanced and that in $d$ the least differentiated. $(\times 228$.

underlying the young epidermis. In the narrow part of the leaf blade the superficial layer of cells also contributes to this sclerenchyma; in other words, some of the sclerenchyma cells are sister cells of the epidermis. The protodermal origin of peripheral sclerenchyma strands has been previously observed in the monocotyledons (Haberlandt, 1914, p. 203-04). Figure $2, F$, illustrates an early stage of development of the 
sheath and of the hypodermal sclerenchyma in connection with the bundle that appears in its entirety in plate $5, B$. The epidermis is not involved in the production of this hypodermal sclerenchyma strand. A similar region in a mature state is depicted in figure $2, G$, prepared from the same section as plate $9, B$. The sheath and the hypodermal sclerenchyma are connected by a narrow strand composed of sclerenchymatous cells similar to those of the sheath; the hypodermal sclerenchyma has somewhat thicker walls. The epidermal cells adjacent to the hypodermal fibers are flatter than elsewhere (fig. 2, $E$ ), even if the protoderm does not contribute cells to the sclerenchyma. It appears as though the cell multiplication which occurs during the formation of the bundle cap and the hypodermal sclerenchyma produces a pressure beneath the epidermis so that the cells of the latter do not expand radially. Plate $6, A$, shows in longitudinal view the region between the protophloem sieve tubes and the epidermis of the leaf containing this protophloem (the upper of the two layers of cells labeled $e p$ ). The young sheath cells and the differentiating hypodermal sclerenchyma cannot be distinguished from each other.

If the bundle is closer to the periphery of the leaf than the bundles in figure $2, F$ and $G$, the merging of the bundle sheath and the hypodermal sclerenchyma is complete. If the bundle is somewhat farther away, narrow elongated cells with thin cellulose walls intervene between the two tissues. Finally, the hypodermal sclerenchyma may be completely dissociated from the bundle.

The Stage of Bundle Differentiation as Related to the Order of Leaf Origin at the Shoot Apex.-Sharman (1942) has related the anatomical development of $Z e a$ leaves to the order of their origin at the apex. Since the shoots used in the present study showed a much slower differentiation than the material described by Sharman, the data are presented for comparison.

This paper will not discuss the longitudinal order of differentiation of the vascular system. The writer agrees, tentatively, with Sharman (1942) : the median procambial strand and its protophloem differentiate acropetally from the axis into the leaf; and the large lateral bundles are clearly evident when they first appear at the base of the leaf, though they cannot be distinguished at lower levels. Sharman concluded that the lateral strands differentiate basipetally into the axis and acropetally into the leaf from somewhere near the base of the leaf. He also assumes that the median strand has a basipetal course in its lower parts within the stem. His view on the developmental course of the smallest bundles has already been given.

Using as an example the shoot partially depicted in figure 1, the 
comparative degree of differentiation of the vascular tissues in the different leaves is as follows:

The shoot was cut consecutively through thirteen internodes. The fifteenth and eighteenth nodes were cut separately. In the latter the long and the short diameters of the axis were $10 \mathrm{~mm}$ and $8 \mathrm{~mm}$ respectively. Leaves 1 to 6 were $0,70,250,570,970$, and 1,640 microns high, respectively; the node-tò-node distances between the nodes 1 and 14 (at these levels the internodes were not differentiated as such or could not be distinguished in cross sections) measured 50, 50, 80, 80, 80, $80,100,160,240,270,520,500$, and 900 microns. Leaf 1 was just initiated, and only the median part of its buttress was discernible, whereas leaves 7 to 13 were cut below their apices. In the shoot of plate 1 the first leaf was a few microns high.

The procambial strand of leaf 1 could be discerned only in the axis (fig. 1, A). Leaf 2 had the median procambial strand in its base. The median strand of leaf 3 reached to 60 microns below the leaf tip; and the laterals were evident at the base of the leaf, but not in the axis. The traces of leaves 2 and 3 had mature sieve tubes. At a level similar to that in plate 1 , the median strand of leaf 4 resembled the bundle shown to the left in plate $2, B$. Farther below, an immature sieve tube occurred, whereas the trace contained mature phloem elements. The median strand of leaf 5 had reached, at levels above figure $1, A$, the stage of development depicted in plate $2, B$, to the right; at lower levels the sieve tube was mature. The median bundle of leaf 6 had two sieve tubes and one xylem element like the bundle in plate $4, A$, except that the xylem element was not yet mature. It had secondary walls, but the protoplasts were still intact. The secondary walls were evident 1,370 microns below the leaf apex and through several internodes in the axis. On each side of the median bundle were two bundles with one or two mature sieve tubes, but without xylem. Still farther toward the leaf margins followed three or four bundles with immature sieve tubes; then several procambial strands without vascular elements. Divisions to form bundles of second rank occurred in leaf 6 (plate 4, $A$, below).

Leaves 1 to 6 , available in their entirety, had not yet ceased their apical growth, as was evidenced by the highly meristematic appearance of their apices. The marginal growth was still evident in leaf 11. These data strikingly contrast with those of Sharman (1942), in whose material plastochrone 6 was characterized by a fully expanded lamina with metaxylem and metaphloem forming basipetally in the sheath undergoing its final elongation, whereas the marginal meristems were becoming inactive in plastochrone 4 .

The median strand of leaf 7 (the first that was cut below its apex) 
of the present study had reached the stage of development depicted in plate $3, B$, to the left. The xylem element was somewhat stretched in the median levels, but not above and below. On one side of the median strand were two bundles with two sieve tubes and one vessel each, the latter not yet stretched. Then followed a strand with an immature tracheary element and some sieve tubes. The others had no xylem. In about three more bundles, mature sieve tubes were present. On the other side of the median the bundle development reached almost the same stage, except that there was still no mature xylem.

The median strand of leaf 8 was somewhat younger than the bundle in plate $5, A$. The first protoxylem vessel was noticeably stretched in the median levels available, but not in the upper sections and not at the insertion of the leaf. Bundles of the third rank in their initial stages of development occurred in the sections of leaf 8 . The median of leaf 9 was somewhat larger than that of 8 , having three mature protoxylem elements. At higher levels the first element had almost disappeared because of stretching and crushing, whereas the second was somewhat stretched. At the base of the leaf, which was noticeably more meristematic than the upper regions, the first element, though slightly stretched, was apparently still intact. The first xylem in the laterals was also somewhat stretched above.

Though the stretching of the first two protoxylem vessels was very pronounced in the median bundle of leaf 10 at higher levels, very little of it occurred below. In leaf 11 the fourth protoxylem vessel was differentiating acropetally; in leaf 12 , the fifth. Both these leaves indicated considerable stretching of the first vessels at their bases. The median strands of leaves 10 to 12 showed the successive early stages of metaphloem and metaxylem differentiation (plates $5, B$, and $7, B$ ). This process was taking place in the basipetal direction, as indicated by the younger appearance of the bundles below. Particularly striking was the disappearance, toward the leaf bases, of the expanding lateral metaxylem vessels. Among the basipetally differentiating elements was also a centrally located vessel, which Sharman (1942) apparently called the last protoxylem. As was mentioned previously, judging by the time of its development it might also be called metaxylem. This central vessel had secondary walls and intact protoplasts above in the median strand of leaf 13. Farther down, the secondary walls were absent; and at the base of the leaf all evidences of metaxylem differentiation had disappeared. Of the five acropetal protoxylem vessels previously formed in the median strand of leaf 13 , four were much stretched above and were associated with a lacuna. In fact, the number of vessels involved in the formation of the lacuna could not be established at the upper 
levels, so pronounced was the rupture of the first three. At the base of the leaf, however, all five vessels were intact, though the first two were much stretched. The first bundles of the second rank had mature sieve tubes in leaf 11; those of the third rank in leaf 13.

The central basipetal vessel was mature above in leaf 14; farther down, the protoplasts were intact; and 650 microns above the union of the leaf with the stem the secondary walls had disappeared. A prominent

TABLE 1

Lengths in Centimeters of the Associated Leaf Blades, Leaf Sheaths, and Internodes of a Vigorously Growing Zea Shoot; and Certain Bunde Charac'reristics of the Internodes*

\begin{tabular}{|c|c|c|c|c|}
\hline $\begin{array}{c}\text { Leaf } \\
\text { and internode } \\
\text { numbert }\end{array}$ & Leaf blade & Leaf sheath & Internode & $\begin{array}{l}\text { Certain bundle characteristics } \\
\text { of the internodes }\end{array}$ \\
\hline 1. & 67 & 1.2 & 0.4 & First protoxylem elements mature \\
\hline $2 \ldots$ & 80 & 2.0 & 0.8 & No protoxylem lacuna \\
\hline $3 \ldots$ & 100 & 4.0 & 1.0 & Lacuna barely indicated \\
\hline $4 \ldots$ & 110 & $\ldots$ & 2.0 & Metaphloem and metaxylem just initiated \\
\hline $5 \ldots$ & 110 & $\ldots$ & 5.0 & $\ldots \ldots$ \\
\hline $6 \ldots$ & 120 & 22.0 & 14.0 & $\begin{array}{l}\text { Lacuna formed, protophloem crushed, lateral } \\
\text { metaxylem vessels still with nuclei }\end{array}$ \\
\hline 7.. & 120 & 24.0 & 22.0 & Metaxylem mature, sheath immature \\
\hline $8 \ldots$ & $\ldots$ & $\ldots$ & 21.0 & Fully mature bundles \\
\hline $9 \ldots$ & $\ldots$ & $\ldots$ & 15.0 & Fully mature bundles \\
\hline $10 \ldots \ldots$ & $\ldots$ & $\ldots$ & 6.0 & Fully mature bundles \\
\hline
\end{tabular}

* Data adapted from Strasburger, 1891.

$\dagger$ Leaves and internodes are numbered consecutively beginning with the youngest; no. 10 is the lowermost on the stem.

lacuna appeared in the place of the first four vessels at higher levels. The fifth vessel was intact. The basipetal central vessel occurred in the same radial row as the acropetal vessels and was in lateral contact with the fifth protoxylem vessel. Below, near the leaf insertion, at least three of the acropetal protoxylem elements were intact. Here the lacuna was absent. The expansion of the central and of the lateral metaxylem vessels had progressed to the base of the leaf.

At higher levels of leaf 15 all the bundles were mature, those of the first rank appearing like the bundle in plate $9, B$. Toward the base, however, part of the metaphloem was still immature, the lateral metaxylem vessels had no secondary thickenings, and the sheath had thin, nonlignified walls. The lowest part of leaf 15 was not available, but the next larger leaf showed at least three intact protoxylem vessels in the median bundle. Finally, leaf 18 showed at the very base the stages of final development of bundles characteristic of the "adult" intercalary meristem. One of the smaller lateral bundles from this region appears in figure 3. The collenchyma is not yet thickened, and the metaxylem not 
yet fully mature. The median bundle showed two intact protoxylem elements, secondary walls and protoplasts in the metaxylem vessels. The metaphloem was almost mature.

As Sharman (1942) has explained, the basipetal maturation of the metaxylem and metaphloem within the leaf is related to the long-delayed intercalary elongation of the leaf sheaths. The relatively slow development of the sheaths is evident from Sharman's (1942, p. 248) table 1 and from Strasburger's (1891, p. 357-61) data. The latter are summarized as table 1 in the present paper. The internodes attain their mature length still later than the sheaths; and the maturation of the vascular bundles in the internodes occurs, as in the sheaths, after their elongation (column 4 in table 1; also Sharman, 1942).

The picture obtained from all these data is as follows: Before and during the elongation of the shoot, the protoxylem and protophloem form connections between the growing organs and the mature parts of the plant. After the elongation, the metaxylem and metaphloem are formed. These tissues mature first in the leaf blade, because it attains its mature length first; then their differentiation progresses through the leaf sheath into the internode, maturing in these organs after they complete their intercalary growth. The bundle sheath matures in the same direction. The special characteristics of the bundle sheath and metaxylem of the intercalary zones of the leaf sheaths and internodes make possible a further, probably limited elongation of these organs.

The continuity of the vascular tissues across the growing regions is maintained, presumably, through the relative structural plasticity and developmental adjustments of the protophloem and protoxylem. The elements of these tissues are capable of some extension in the mature state without, apparently, being destroyed. With further stretching they are destroyed, but the protoxylem (and protophloem) elements differentiate one after the other and are destroyed in a similar succession. Such method of growth would seem to provide some intact elements during the entire period of elongation, until afterwards the metaxylem and metaphloem mature in the completed internode and sheath.

Sharman (1942, p. 274) assumes, however, that when the protoxylem is ruptured in the elongating organs the leaf has no direct connections with the stem by means of differentiated water-conducting cells and that therefore the water must move part of its way across living cells. Sharman's own data do not prove this point. One might surmise that in table II (Sharman, 1942, p. 268) leaf 6 illustrating the basipetal differentiation of the metaxylem is left without xylem elements between levels 34 and 37. His text figure 21 (p. 270), however, indicates the presence of intact protoxylem at both these levels. The condition of the 
xylem in the remaining $4 \mathrm{~cm}$ of this leaf is not mentioned. Similarly, in all other illustrations, immature metaxylem is associated with some intact protoxylem in the same bundle.

In the present writer's experience, eosin solution passes readily through the elongating internodes and leaf sheaths of $Z e a$ and other grasses, just as it would pass through open water-conducting channels. Under the dissecting microscope the stained bundles appear entirely continuous and (in materal stained with phloroglucinol and hydrochloric acid) show some mature water-conducting elements in sections taken at different levels; metaxylem elements at the higher, more mature regions of the leaf; and protoxylem elements in the growing zones. The data obtained from the paraffin sections, given earlier in this paper, also indicate continuity of the conducting channels across the active intercalary meristems. Further studies using a wide range of material would be desirable to test the value of Sharman's assumption.

\section{DISCUSSION}

In the present paper the terms protophloem and metaphloem, protoxylem, and metaxylem are used in the sense in which they were originally conceived and in keeping with the writer's views as previously expressed (Esau, 1943). In this classification of the primary vascular tissues the relation of their development to that of the organ or plant as a whole is more important than their morphological characteristics. Thus employed, the concepts of protophloem and metaphloem, protoxylem and metaxylem serve the distinctly useful purpose of giving a dynamic picture of plant structure and of clarifying the relation between the development of the plant and the function of the vascular system. The protophloem and the protoxylem are quickly initiated in the shoot apex and (through their relative structural and developmental plasticity) maintain the continuity of the conductive channels in the growing regions. The less plastic but more elaborate metaphloem and metaxylem assume the function after the plant organs reach their mature size. Though the statement above consists of well-known facts, the repetition seems justified in view of various recent attempts to reevaluate the categories of the primary vascular tissues, to give them new meanings, or even to discard the classification entirely-all on the basis of very limited morphological or developmental facts. (See review by Esau, 1943.)

Incidentally, the vascular bundles of $Z e a$ (and probably of other Gramineae) offer excellent class material to show the student the distinctive features of the successive parts of the primary phloem and primary xylem. In contrast to Stover's (1934) results, the present study 
demonstrates a rather clear distinction between the protophloem and metaphloem of $Z e a$.

The present investigation bears upon the problem of the developmental relation between the bundle sheaths and the vascular tissues of the Gramineae. These sheaths obviously develop as integral parts of the vascular bundle. Similarly related to the vascular tissues from the developmental standpoint are all the different types of sheaths in Zea -that is, the parenchymatous sheaths of the small bundles within the leaf blade, the sclerenchymatous sheaths of the large and small bundles in the other parts of the plant, and finally the collenchymatous sheaths in the intercalary region. The compound bundles of the intercalary zone show in a most striking manner the close relation between the sheath and the vascular tissues: additional vascular strands develop within the bundle cap of an earlier, larger strand. Strasburger's (1891, p. 345) classification of all bundle sheaths in Zea as parts of the stele ("Stelolemmae") seems practical.

This classification involves, however, some difficulties. The bundle sheaths, particularly the collenchymatous and the sclerenchymatous, cannot be sharply separated, on the basis of origin, from the adjacent parenchyma and from the sclerenchyma strands that do not constitute parts of the bundles. The similar origin and development of the intraand extra-fascicular sclerenchyma illustrate Foster's (1942, p. 32) statement that "the nomenclature and classification of cell types and 'tissues' is still in a confused and uncertain state." Classifying the fibers, Foster (1942, p. 74) follows Haberlandt (1914, p. 152-55) in placing all the extracambial fibers into the group of "bast" fibers. The sclerenchyma of the monocotyledons also belongs in this category. As Foster states, this is a "topographical" classification; it is doubtless the most convenient at present. Haberlandt (1914, p. 199-202) goes even further in identifying the extra- and intrafascicular fibers by interpreting the meristem giving rise to the extrafascicular fibers as procambium. Plate $6, A$, in the present paper shows how such a concept could be formulated : the procambium between the xylem and phloem displays the same morphology as the meristem between the protophloem and the epidermis that forms the bundle sheath and the extrafascicular hypodermal sclerenchyma. Further comparative developmental studies are needed before Haberlandt's use of the term procambium can be properly evaluated.

The procambium that gives rise to the vascular bundles in $Z e a$ shows a predominance of tangential divisions, a tendency most pronounced in the late stages of bundle development. This method of division causes a resemblance between the procambium and the cambium of the dicoty- 


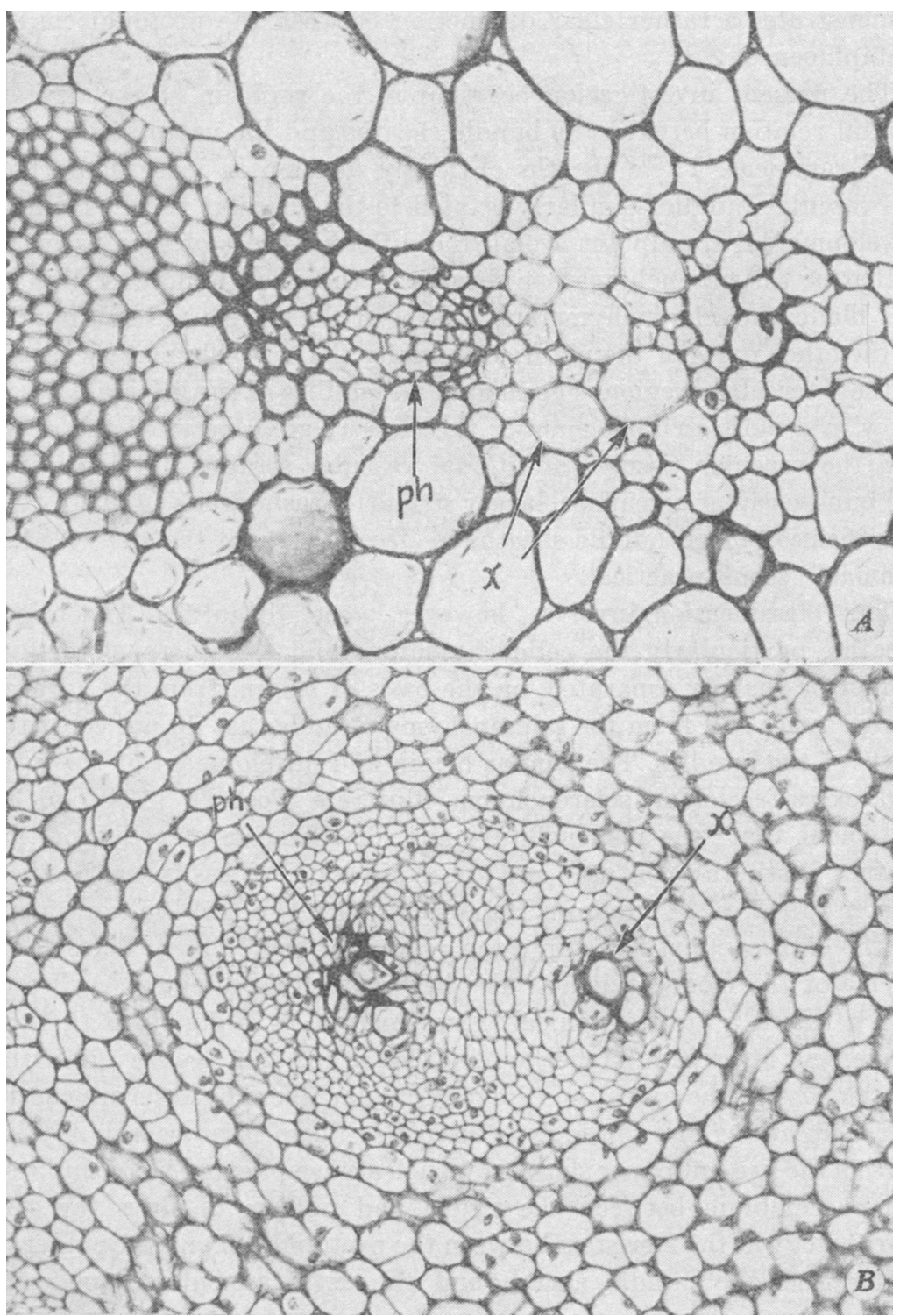

Figure 4.- $A$, Transverse section of a vascular bundle from a leaf of Iris germanica, showing the orderly radial seriation of the mature metaphloem $(p h)$. The xylem $(x)$ appears to the right of the phloem. $B$, Transverse section of a vascular bundle from a young leaf of Cocos nucifera, illustrating the cambiumlike appearance of the meristem that gives rise to the metaphloem and metaxylem. The protophloem $(p h)$ and the protoxylem $(x)$ are differentiated in this bundle. $($ Both $\times 250$.) (From slides lent by Dr. V.I. Cheadle.) 
ledons as seen in transverse sections. The radial seriation of the procambium cells is very common in the monocotyledons. Thus figure $4, B$, shows an immature bundle of a Cocos leaf, with orderly aligned meristematic cells between the protoxylem and the protophloem. The literature contains many more examples. (See review by Esau, 1943.) Sometimes the radial seriation is clearly maintained by the mature tissues, as in the instance of the metaphloem of Iris in figure 4, A. As previously emphasized (Esau, 1943), the problem of tissue classification has been only confused by the attempts of many workers (recently Sharman, 1942) to use the radial seriation of the meristematic cells as the principal criterion for distinguishing between the procambium and the cambium. A broad flexible classification, taking into consideration developmental aspects of the plant as a whole, has already been advocated by the writer in reference to the vascular meristems, as well as the vascular tissues (Esau, 1943). All the vascular tissues of Zea are here interpreted as primary and arising from procambium. These vascular tissues are a part of the wholly primary plant body. In certain arborescent monocotyledons the primary body is amplified by the addition of secondary tissues (mainly vascular).

Recently Moreland and Flint (1942, p. 361) interpreted the cross connections in the sheath of the sugar cane as secondary because "they arose from living cells that had become permanent and then returned to the meristematic condition." Modern morphologists of course regard living parenchyma cells (or, indeed, any living cell) not as "permanent," but as potentially meristematic (Hayward, 1938, p. 14; Bloch, 1941; Foster, 1942, Exercise III and p. 58; and others). Almost obsolete, therefore, is the distinction of the secondary tissues from the primary on the basis that the former arise from cells that returned to the meristematic condition. The present study, furthermore, by comparing the development of the cross connections with that of the other bundles, has revealed a whole series of transitions from the bundles of the first rank (formed within the still rather densely cytoplasmic cells) to the smallest bundles that arise in highly vacuolated parenchyma. The cross connections are parts of the primary vascular systems of the wholly primary plant bodies of corn and sugar cane.

\section{SUMMARY}

The procambial strands of $Z e a$ mays are initiated through longitudinal divisions in localized areas of the differentiating organs. The procambium of the largest strands is formed first in the still comparatively dense cytoplasmic parts of the shoot. The smaller bundles arise later in the more highly vacuolated part. A series of transitions occur 
between the largest and the smallest bundles with regard to relative time of appearance in the differentiating organs and also with regard to the degree of vacuolation of the parenchyma from which the procambium arises.

More cells subdivide in the formation of the larger strand than in the development of the smaller ones. In its origin the procambium is not sharply separated from the adjacent parenchyma : when cells divide to produce procambium, part of a cell may become added to the procambium, while the other part may remain outside.

After the procambial strand is delimited, it increases in thickness by divisions within it. Radial growth dominates over the tangential; that is, tangential divisions predominate. As the bundle advances in its development, this orientation of the planes of division becomes increasingly evident. Despite the cambiumlike appearance of the vascular meristem, it is here interpreted as procambium, and all the vascular bundles in the whole plant are considered to be primary.

The first protophloem sieve tubes mature before the first protoxylem vessels. The protophloem is composed of sieve tubes only. In this it contrasts with the metaphloem, in which companion cells are associated with the sieve tubes. The protophloem is gradually crushed while the metaphloem matures. In like manner the conducting elements of the protoxylem are gradually destroyed while the metaxylem matures.

The bundle sheath differentiates partly from the outermost layer of the procambium strand, partly by addition of cells from the adjacent parenchyma, which undergo longitudinal divisions. Thus the bundle sheath is a part of the vascular bundle, but is not sharply separated from the tissue outside the bundle. The bundle sheath may be confluent with the hypodermal sclerenchyma, which arises partly like the peripheral sheath cells, by divisions and elongation of parenchyma cells, partly from the derivatives of the protoderm.

The protophloem and protoxylem are the conducting tissues of the elongating part of the shoot. The maturation of the metaphloem and metaxylem is delayed until the organs complete their elongation. 


\section{LITERATURE CITED}

ARTSCHWAGER, E. F.

1925. Anatomy of the vegetative organs of sugar cane. Jour. Agr. Res. 30: 197-221.

BLOCH, R.

1941. Wound healing in higher plants. Bot. Rev. 7:110-146.

Cheadle, V. I.

1942. The occurrence and types of vessels in the various organs of the plant in the Monocotyledoneae. Amer. Jour. Bot. 29:441-50.

Cheadle, V. I., and N. B. Whitrokd.

1941. Observations on the phloem of the Monocotyledoneae. I. The occurrence and phylogenetic specialization in structure of the sieve tubes in the metaphloem. Amer. Jour. Bot. 28:623-27.

Esau, K.

1936a. Ontogeny and structure of collenchyma and of vascular tissues in celery petioles. Hilgardia 10(11):431-76.

1936b. Vessel development in celery. Hilgardia 10(11):479-88.

1938. Ontogeny and structure of the phloem of tobacco. Hilgardia 11(8):343424 .

1939. Development and structure of the phloem tissue. Bot. Rev. 5:373-432.

1940. Developmental anatomy of the fleshy storage organ of Daucus carota. Hilgardia 13(5):175-226.

1941. Phloem anatomy of tobacco affected with curly top and mosaic. Hilgardia $13(8): 437-90$.

1943. Origin and development of primary vascular tissues in seed plants. Bot. Rev. 9:125-206.

EsAu, K., and Wm. B. HewitT.

1940. Structure of end walls in differentiating vessels. Hilgardia 13(5):229-44.

Evans, M. W., and F. O. Grover.

1940. Developmental morphology of the growing point of the shoot and the inflorescence in grasses. Jour. Agr. Res. 61:481-520.

Foster, A. S.

1942. Practical plant anatomy. 155 p. D. Van Nostrand Company, New York, N. Y.

Frey-Wrssling, A.

1940. Zur Ontogenie des Xylems in Stengeln mit sekundärem Dickenwachstum. Deut. Bot. Gesell. Ber. 58:166-81.

HABERLANDT, G.

1914. Physiological plant anatomy. 777 p. Macmillan and Company, London.

HAYWARD, H. E.

1938. The structure of economic plants. 674 p. The Macmillan Company, New York, N. Y.

Moreland, C. F., and L. H. Flint.

1942. The development of vascular connections in the leaf-sheath of sugarcane. Amer. Jour. Bot. 29:360-62.

РотоNié, H.

1886. Entwickelung der Leitbündel-Anastomosen in den Laubblättern von Zea Mays. Deut. Bot. Gesell. Ber. 4:110-12.

RöSLER, P.

1928. Histologische Studien am Vegetationspunkt von Triticum vulgare. Planta $5: 28-69$. 
Sharman, B. C.

1942. Developmental anatomy of the shoot of Zea mays L. Ann. Bot. (London) $6: 245-82$.

STOVER, E. L.

1934. Development and differentiation of tissues in the stem tip of grasses. Ohio Jour. Sci. 34:150-60.

StrasbuRGer, E.

1891. Ueber den Bau und die Verrichtungen der Leitungsbahnen in den Pflanzen. Histologische Beiträge. vol. 3. 1,000 p. Gustav Fischer, Jena.

TroLL, W.

1935. Vergleichende Morphologie der höheren Pflanzen. Vol. 1: Vegetationsorgane. 1. Lieferung. Gebrüder Borntraeger, Berlin. 
PLATES 



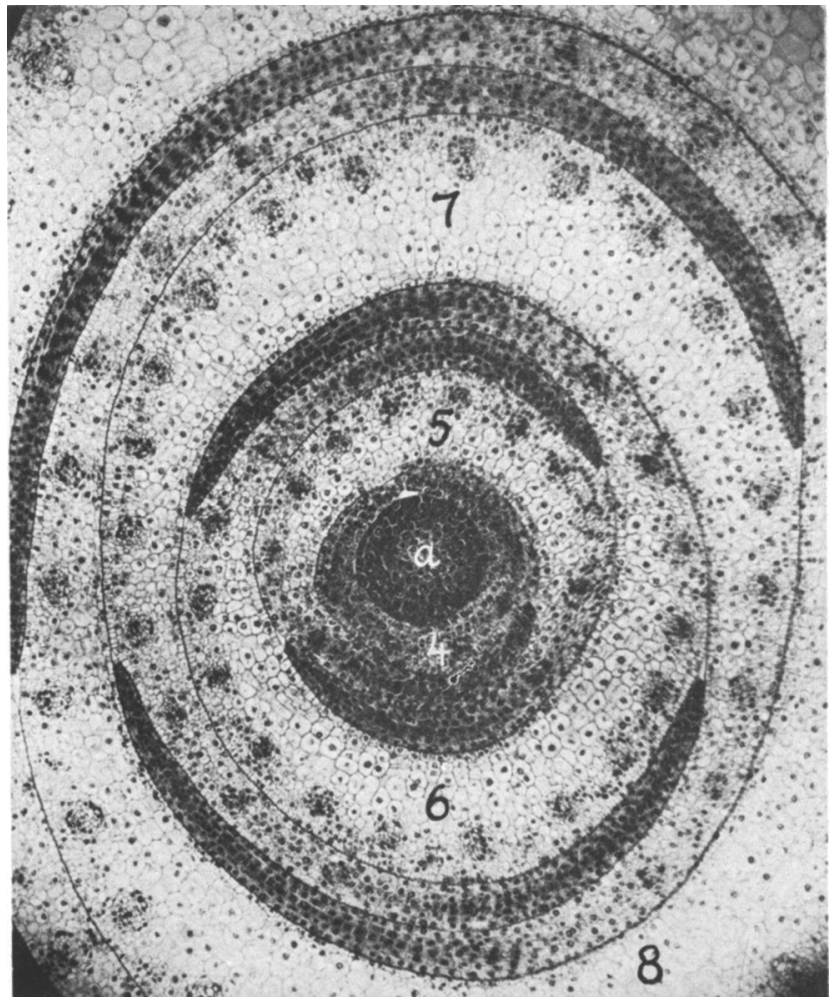

Plate 1.-Transverse section through the apex of a shoot, showing the stem apex (a) and the leaves enclosing the stem. The youngest leaf visible in this section was the fourth from the apex. Therefore the leaves in this figure are numbered 4 to 8 . The three younger leaves occurred in sections cut at lower levels of the shoot. $(\times 77$.) 

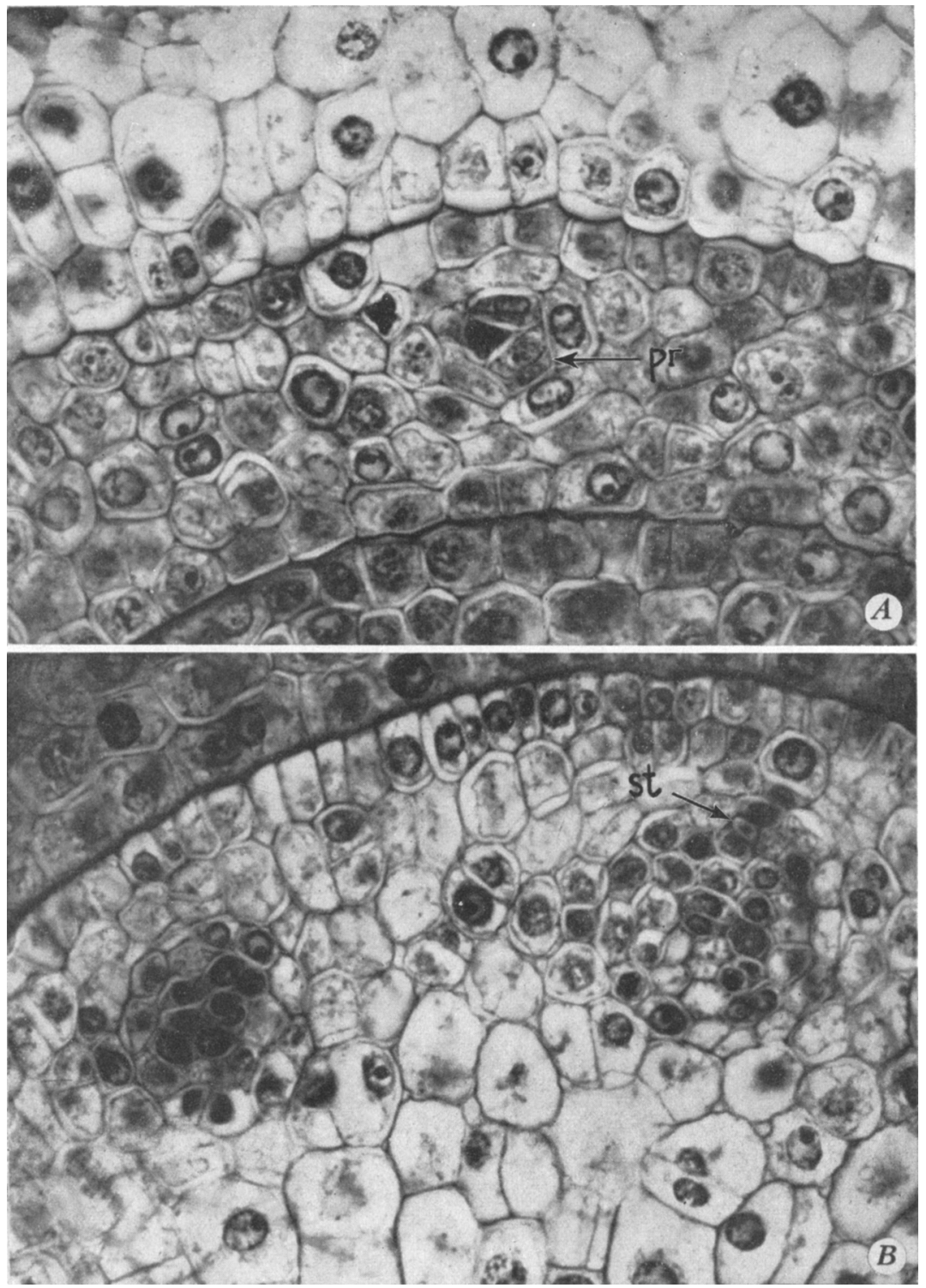

Plate 2.-Transverse sections of parts of leaves, showing early stages in the differentiation of the procambium. In $A$ appears the very young median procambial strand $(p r)$ of the second leaf below the apex. $B$ shows the median (right) and the adjacent lateral (left) bundles of the fifth leaf below the apex (leaf 5 in plate 1 ). The median bundle has an immature sieve tube $(s t)$. $($ Both $\times 750$. 

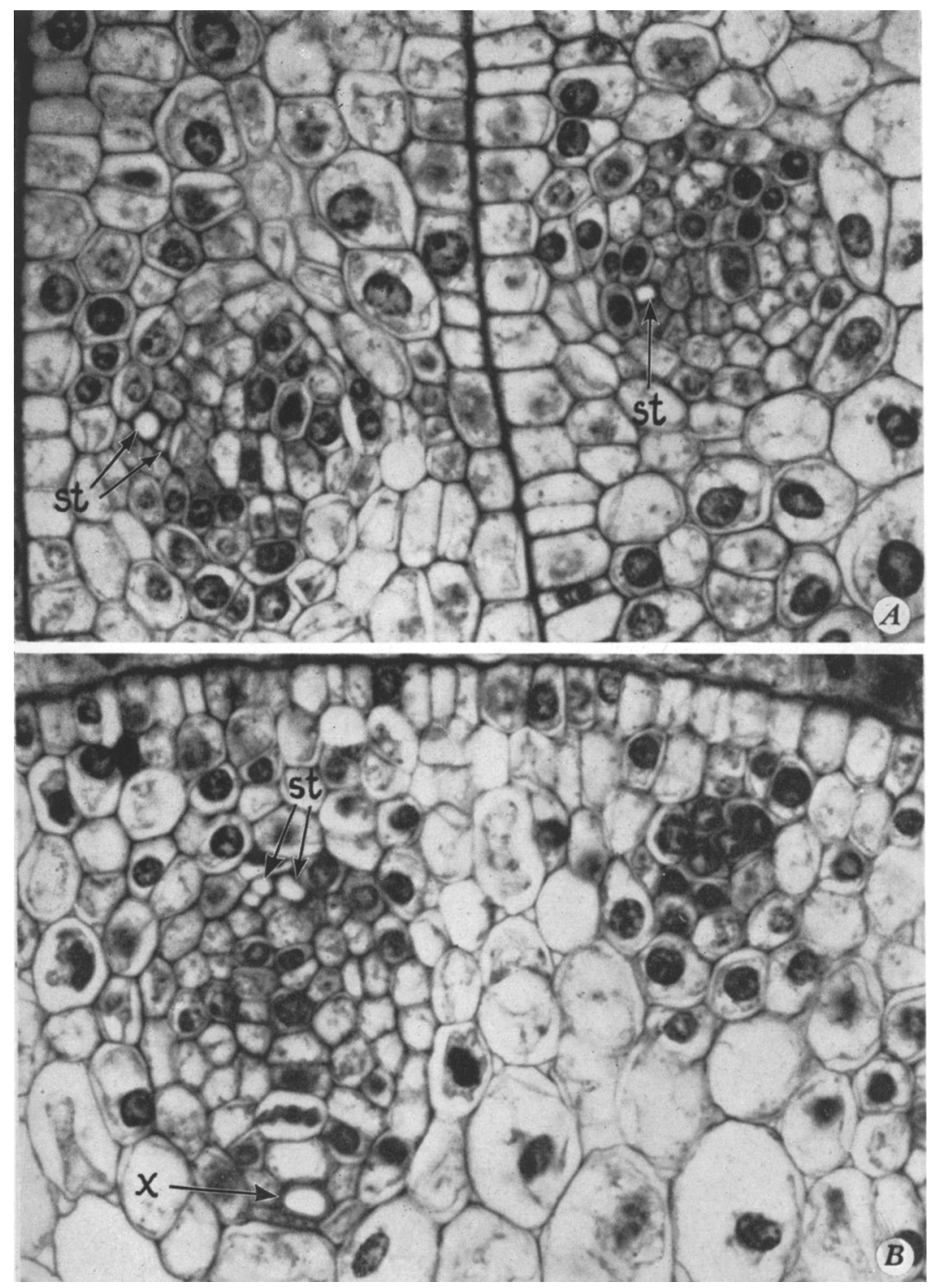

Plate 3.-Transverse sections of parts of leaves, showing early stages of vascular differentiation in the procambial bundles. In $A$ is illustrated two first-rank lateral bundles, one (right) from the seventh, the other (left) from the eighth leaves below the apex. In each bundle the first sieve tube (st) is mature. In the bundle to the left the second sieve tube is almost mature. At $B$ is shown, to the left, the median strand of leaf 7 with three mature sieve tubes (st) and one mature xylem element $(x)$. A small procambial strand of second rank (bundle II in fig. $1, D$ ) appears to the right in $B$. (Both $\times 750$.) 

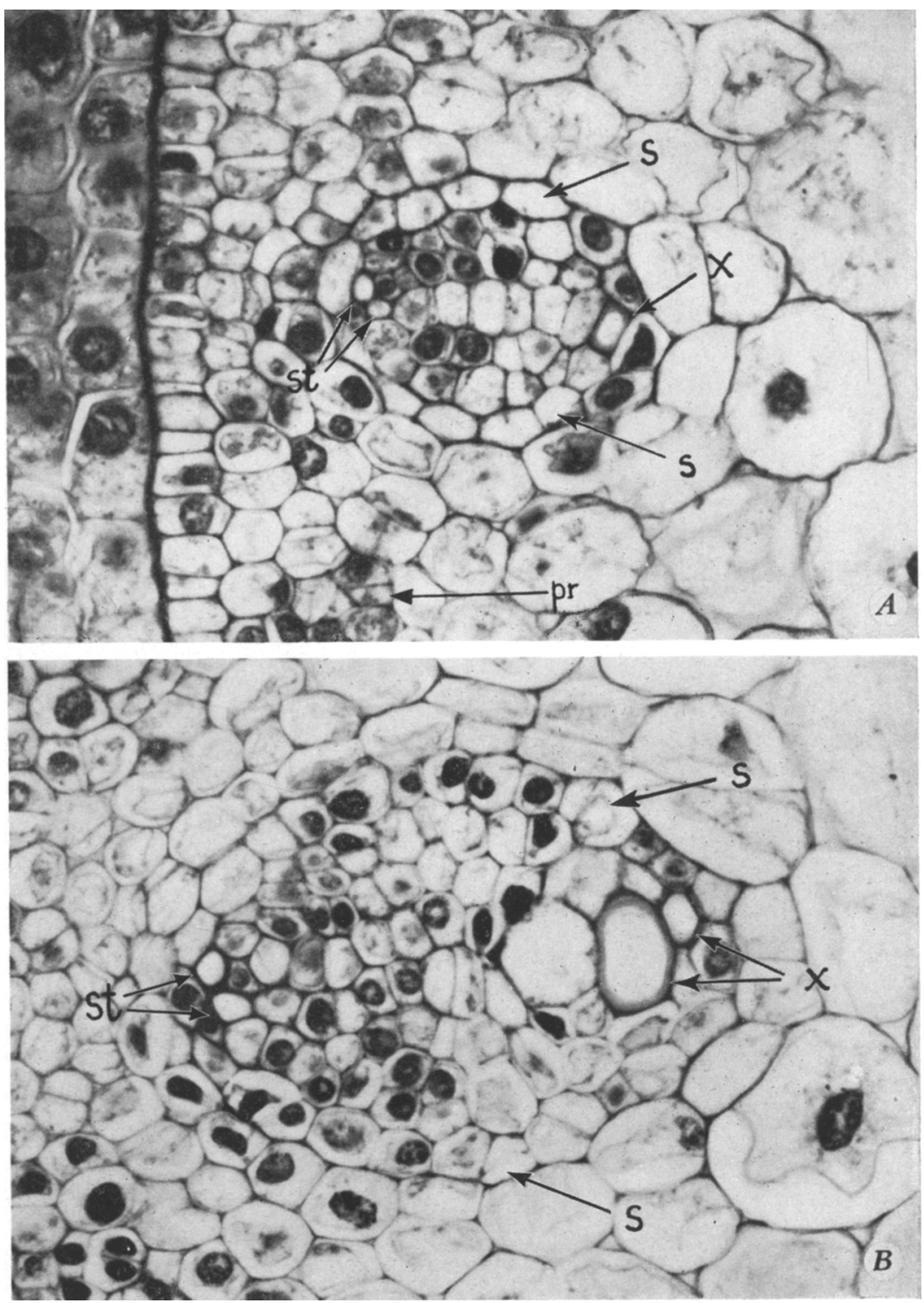

Plate 4.-Transverse sections of bundles from the sixth $(A)$ and eighth $(B)$ leaves below the apex. These were bundles of the first rank (bundles I in figure $1, D$ ) located next to the median strands. The bundle in $A$ shows two sieve tubes and two xylem elements. The smaller of the two xylem elements in $B$ has been stretched somewhat, and the ringlike secondary wall
thickening appears slightly tilted. Details are: $p r$, procambium; $s$, sheath; st, sieve tube;
$x$, xylem element. (Both $\times 750$.) 


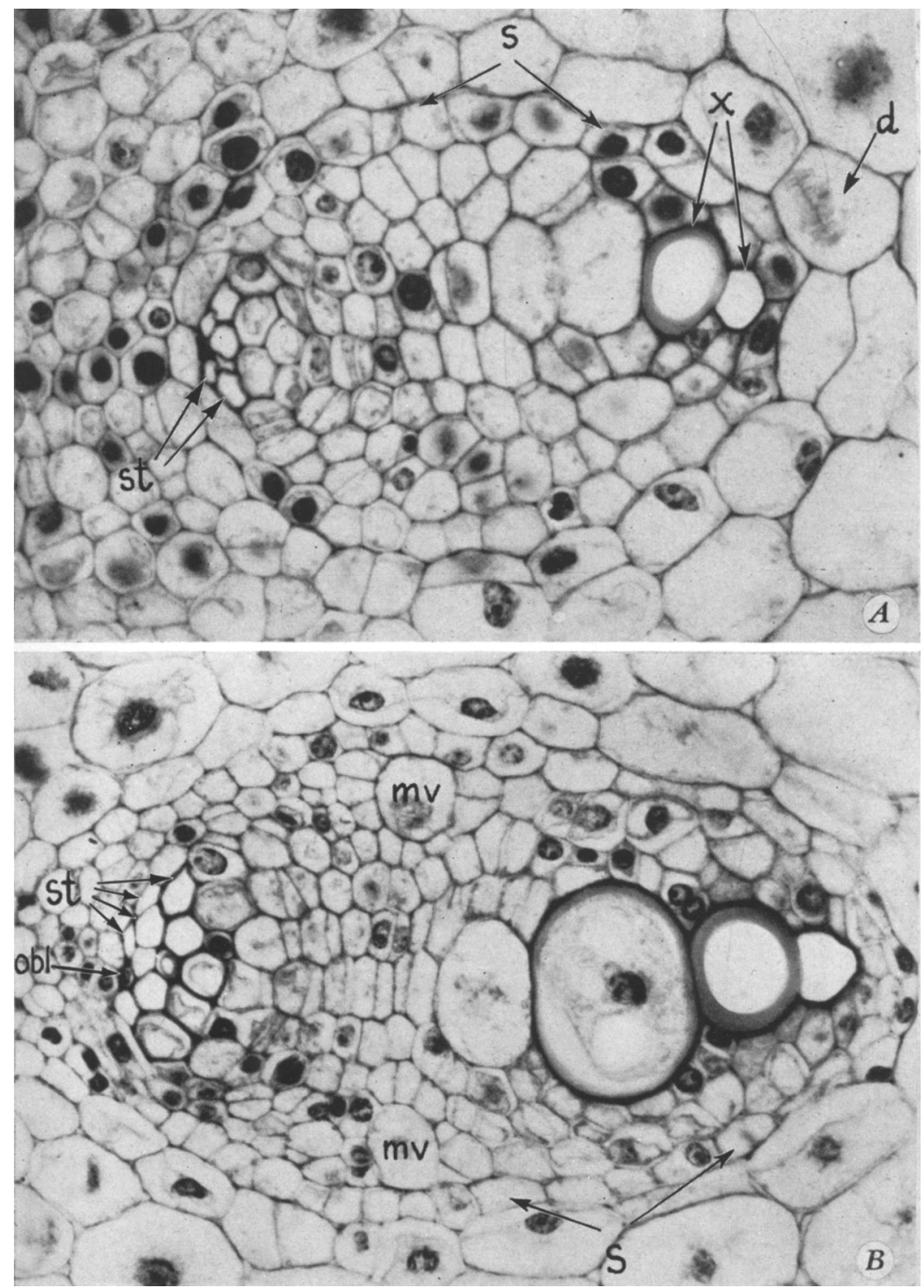

Plate 5.-Transverse sections of bundles showing an earlier $(A)$ and later $(B)$ stages in the differentiation of the protophloem and protoxylem. $B$ shows also the early stage of metaphloem and metaxylem development. The bundle in $A$ occurred in the tenth, the bundle in $B$ in the thirteenth leaves below the apex. Both were lateral bundles of the first rank. Details are: $d$, dividing cell; $m v$, lateral metaxylem vessels; $s$, bundle sheath; st, sieve tube; $x$, xylem element. $(A, \times 750 ; B, \times 480$. $)$ 


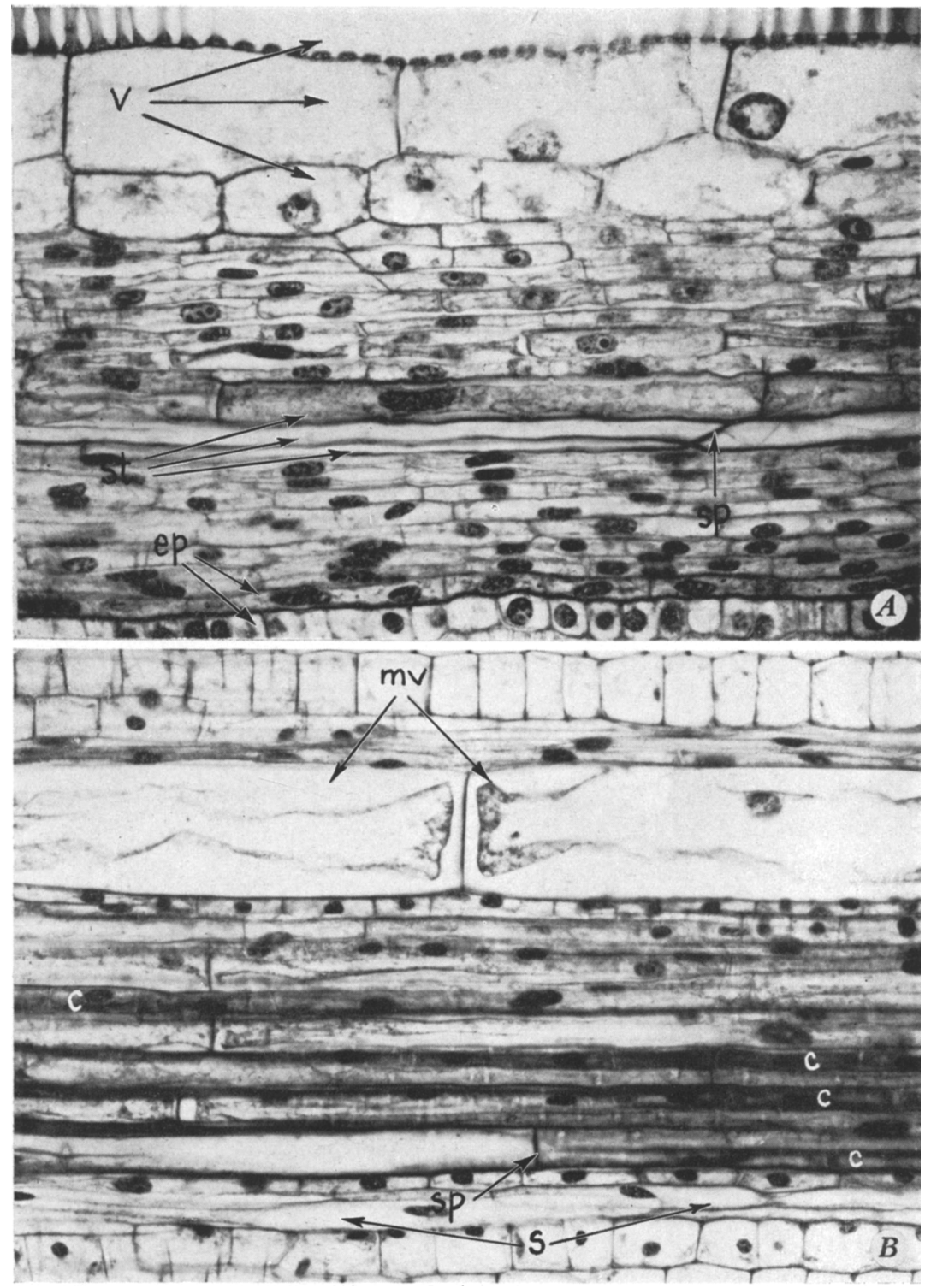

Plate 6.-Longitudinal sections of a younger $(A)$ and an older $(B)$ vascular bundle. The bundle in $A$ was somewhat older than the bundle in plate $5, A$; the bundle in $B$ was comparable with the one in plate 9, $A$. Details are: $c$, companion cell; $e p$, epidermis (the two adjacent layers of epidermis belong to two different leaves); $m v$, metaxylem vessel element; $s$, sheath; $s p$, sieve plate; st, sieve tube; $v$, vessel or vessel element. $(A, \times 400 ; B, \times 290$.) 


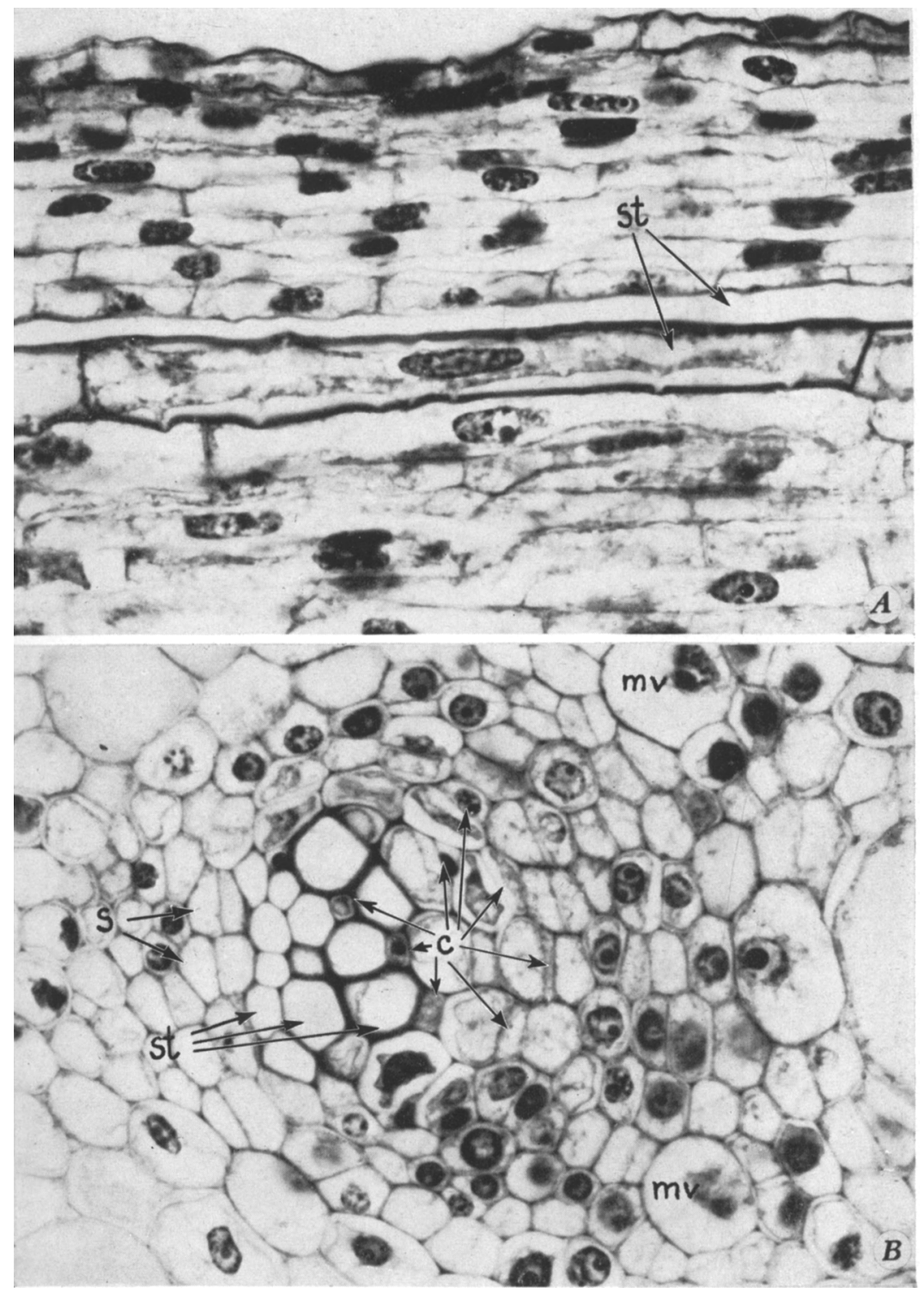

Plate 7.-A, Longitudinal section of a vascular bundle, showing a differentiating metaphloem sieve-tube element (lower cell labeled st) with pitted nacré walls and a portion of an old and much elongated protophloem sieve tube (upper cell labeled $s t$ ). $B$, Transverse section of part of a bundle showing mature protophloem (thin-walled cells apparently without contents to the left in the bundle). The first sieve tubes of the metaphloem with nacré walls and companion cells occur to the right of the protophloem. The sheath cells $(s)$ outside the protophloem have divided by periclinal walls. Details are: $c$, companion cell; $m v$, metaxylem vessel; $s$, sheath ; st, sieve tube. (Both $\times 750$.) 


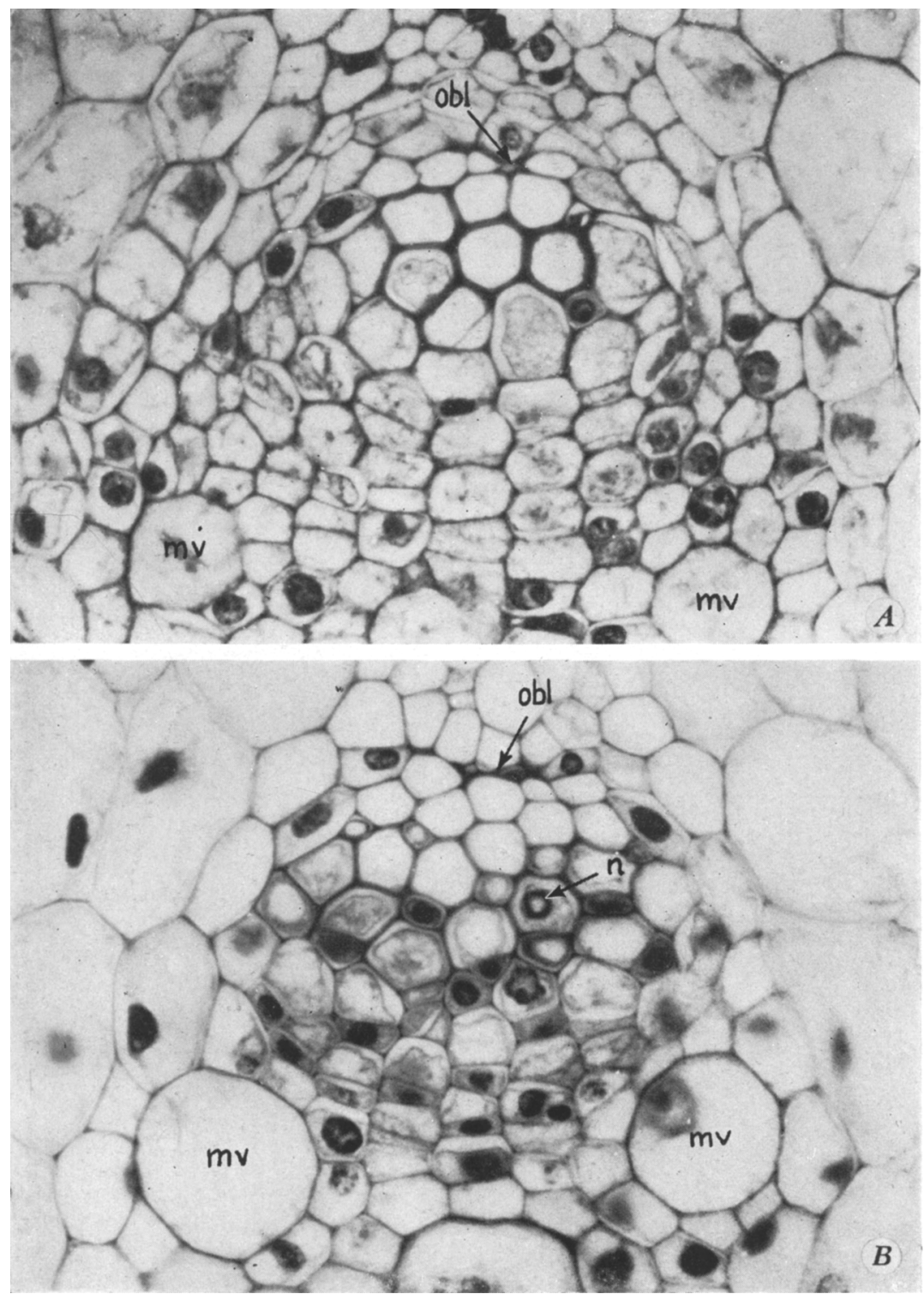

Plate 8.-Transverse sections of parts of bundles showing two stages in phloem differentiation. In $A$ is illustrated the beginning of protophloem crushing at obl and an early stage in metaphloem development. At $B$ is depicted the stage of active metaphloem differentiation. Details are: $m v$, metaxylem vessel; $n$, nucleus; $o b l$, obliterated protophloem. (Both $\times 750$.) 

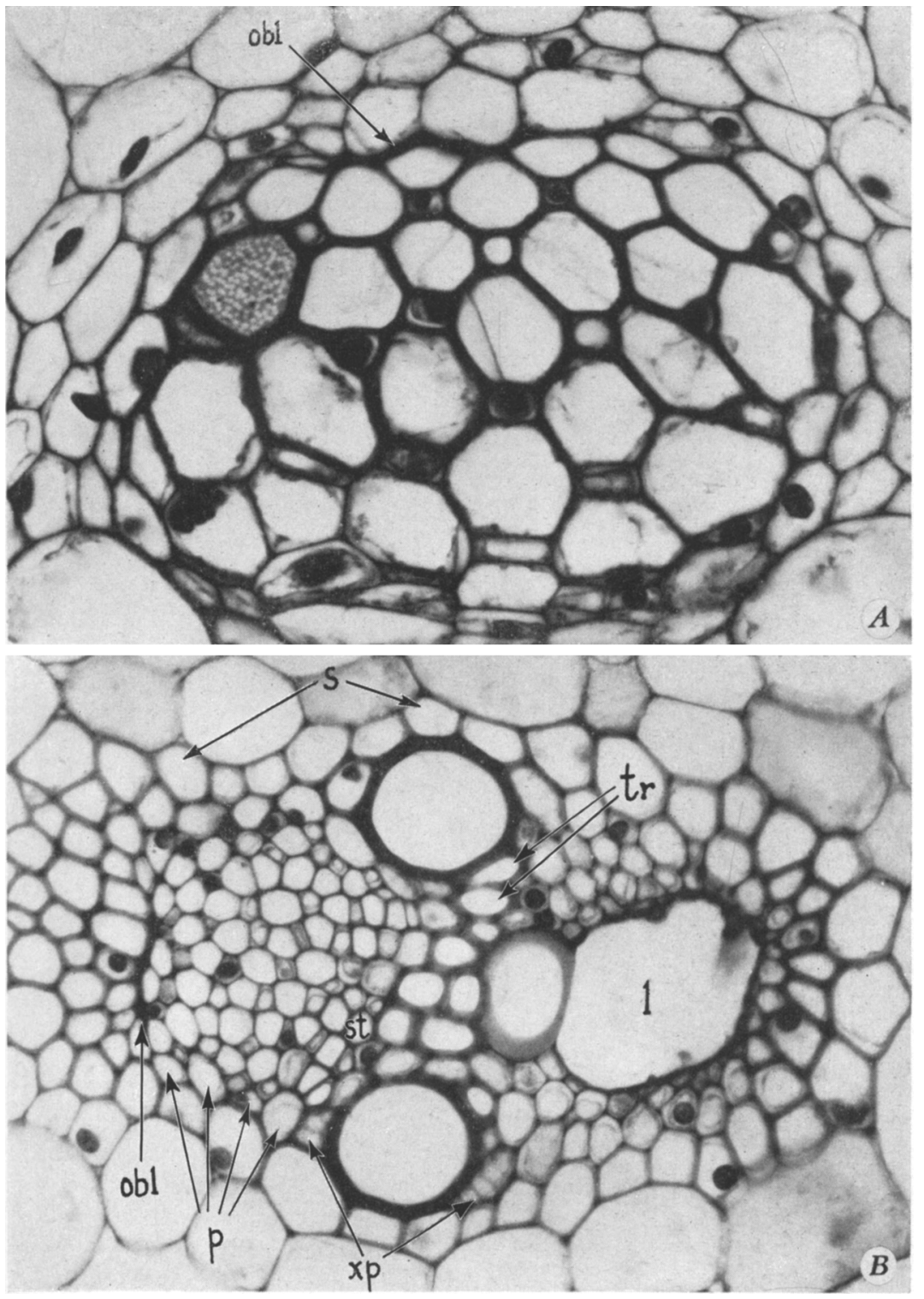

Plate 9. $-A$, Transverse section of almost mature metaphloem from a bundle in an internode. The protophloem is obliterated $(o b l)$. The first metaphloem sieve tubes are somewhat smaller than the later. A sieve plate is visible in one of the sieve tubes to the left. $B$, A mature vascular bundle from leaf 15 in transverse section. Details are: $l$, lacuna of the protoxylem; obl, obliterated protophloem; $p$, parenchyma; $s$, sheath; st, sieve tube; $t r$, tracheary element; $x p$, xylem parenchyma. $(A, \times 750 ; B, \times 480$. $)$ 


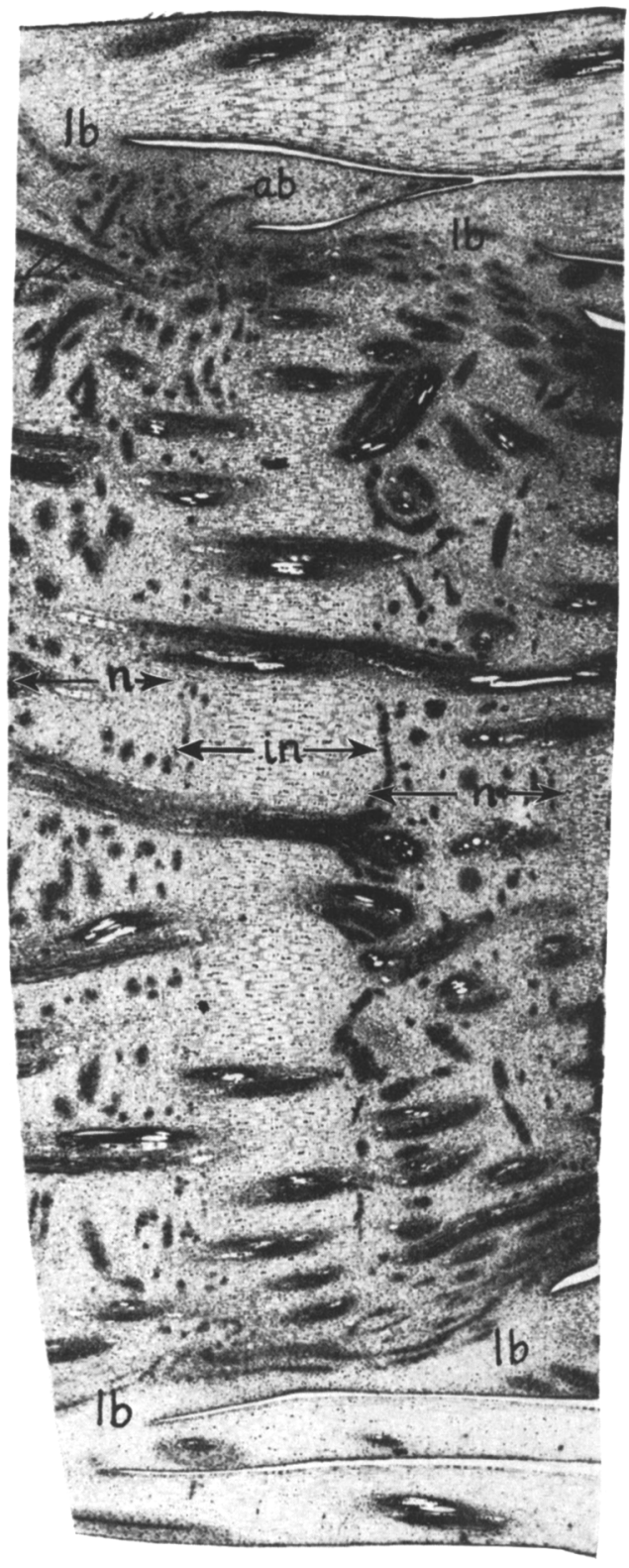

Plate 10.-Longitudinal section through two nodes $(n)$ and an internode (in). The leaf bases (lb ) attached to these nodes are approximately the sixteenth and seventeenth from the apex. A part of an axillary bud appears at $a b$. The figure illustrates the continuity of the vascular bundles from node to node across the elongating internode. $(\times 20$.) 